\title{
Analysis of the Interactions Taking Place in the Recognition Site of a Bimetallic Mg(II) - Zn(II) Enzyme, Isopentenyl Diphosphate Isomerase. A Parallel Quantum-Chemical and Polarizable Molecular Mechanics Study
}

\author{
Nohad Gresh, ${ }^{* \dagger}$ Nicole Audiffren, $\stackrel{\ddagger}{\ddagger}$ Jean-Philip Piquemal, ${ }^{\S}$ Jerome de Ruyck,,$"$ Marie Ledecq, $\stackrel{ }{\|, \perp}$ \\ and Johan Wouters" \\ Laboratoire de Pharmacochimie Moléculaire et Cellulaire, U648 INSERM, UFR Biomédicale, Université Paris \\ Descartes, 45 rue des Saints-Pères, 75006 Paris, France, Centre Informatique National de l'Enseignement \\ Supérieur, 950, rue de Saint Priest, 34097 Montpellier, France, Laboratoire de Chimie Théorique, Centre \\ National de la Recherche Scientifique, UMR 7616, Université Pierre et Marie Curie, 4 place Jussieu, \\ 75252 Paris Cedex 05, France, and Laboratoire de Chimie Biologique Structurale, FUNDP, 61 Rue de \\ Bruxelles, B-5000 Namur, Belgium
}

Received: August 7, 2009; Revised Manuscript Received: January 20, 2010

Using the SIBFA polarizable molecular mechanics procedure, we analyze the binding energy of a bimetallic $\mathrm{Mg}(\mathrm{II}) / \mathrm{Zn}$ (II) enzyme, isopentenyl diphosphate isomerase, to an inhibitor built up of a trianionic diphosphate and of a cationic ethyldimethylammonium (EDMA) moiety. The analyses are performed on the protein recognition site, which totals 13 residues, as well as on some "mutants" in which one selected residue is removed at a time. They are also carried out for the individual recognition sites, namely, EDMA, $\mathrm{Mg}(\mathrm{II})$, and $\mathrm{Zn}(\mathrm{II})$. Comparisons are done with ab initio quantum chemistry (QC) results on all considered sites, with different basis sets and at different levels of correlation. The SIBFA computations reproduce the evolutions of the QC interaction energies in the recognition site and its "mutants". For such sites, small $(<2-3 \%)$ relative errors are found after the BSSE correction is done. Such close agreements can conceal, however, some shortcomings found in the individual binding sites, which QC energy decomposition analyses can identify.

\section{Introduction}

Isopentenyl diphosphate isomerase (IDI) is a bimetallic $\mathrm{Zn} /$ $\mathrm{Mg}$ metalloenzyme which catalyzes the isomerization of isopentenyl diphosphate (IPP) into dimethylallyl diphosphate. ${ }^{1}$ The $\mathrm{Mg}$ (II) cation is involved in binding of the diphosphate moiety of ligands, either substrates/products or inhibitors, while $\mathrm{Zn}$ (II) has a structural role and is coordinated by a glutamate essential to the catalytic mechanism of the enzyme. The structure of IDI in complex with $\mathrm{N}, \mathrm{N}$-dimethyl-2-amino-1-ethyl diphosphate (NIPP), an inhibitor acting as a transition state analogue, has been solved by X-ray crystallography. ${ }^{2}$ It is represented in Figure $1 \mathrm{a}$, and the structure of NIPP is shown in Figure 1b. This complex has three distinct domains, the energy features of which we wish to investigate by polarizable molecular mechanics (PMM) computations and ab initio quantum chemical (QC) computations performed in parallel. Figure 2 shows the interactions taking place between NIPP and the IDI recognition site.

(1) In the Mg binding domain, the NIPP diphosphate binds $\mathrm{Mg}$ (II) through one anionic oxygen from each phosphate group. $\mathrm{Mg}$ (II) is in addition monocoordinated by Glu116, the Cys67 main chain, and by two water molecules. Diphosphate, which has a total net charge of -3 , is additionally stabilized by ionic interactions with four basic residues, namely, Lys21, Arg51, Lys55, and Arg83. The terminal, dianionic phosphate, has

\footnotetext{
* To whom correspondence should be addressed. E-mail: nohad.gresh@ parisdescartes.fr.

† Université Paris Descartes.

* Centre Informatique National de l'Enseignement Supérieur.

$\S$ Université Pierre et Marie Curie.

"FUNDP.

${ }^{\perp}$ Present address: UCB Pharma S.A., Chemin du Foriest, B-1420 Braine l'Alleud, Belgium.
}

a)

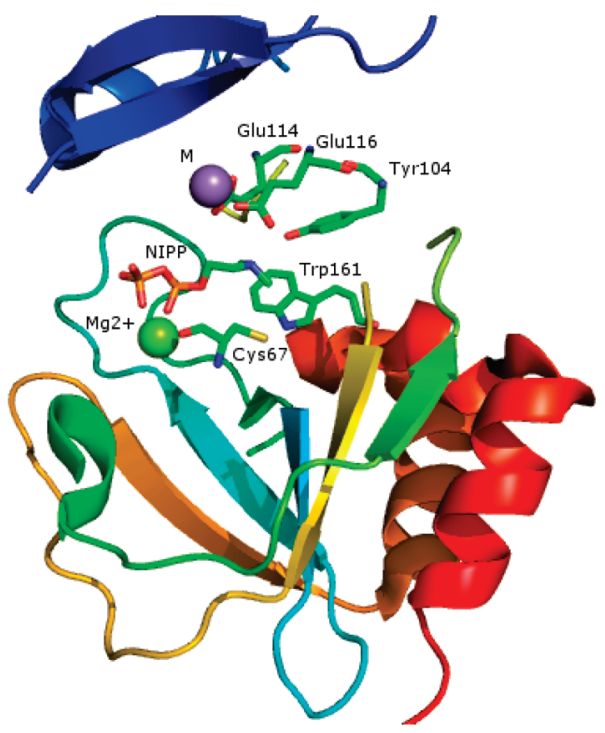

b)

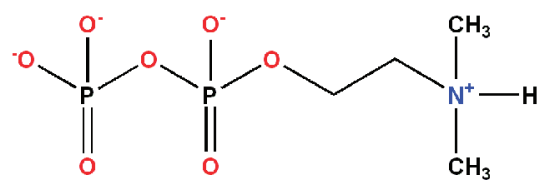

Figure 1. Representation of (a) the three-dimensional structure of IDI and (b) the molecular structure of the NIPP inhibitor.

$\mathrm{H}$-bond interactions with the $\mathrm{NH}$ group of a His residue in the neighboring $\mathrm{Zn}$ (II) binding site. The monoanionic phosphate binds through its ester $\mathrm{O}$ to one $\mathrm{Mg}(\mathrm{II})$-coordinating water, Wat ${ }_{1}$, which in turn acts as an H-bond acceptor from the second 


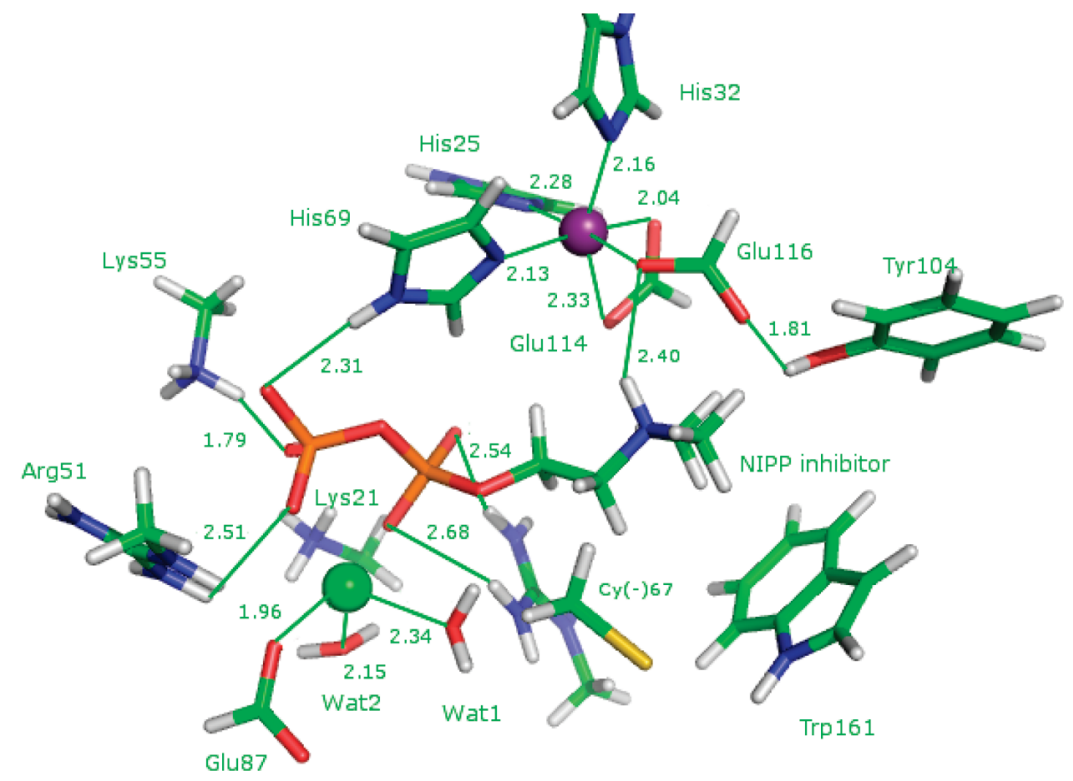

Figure 2. Representation of the IDI-NIPP complex.

$\mathrm{Mg}$ (II)-coordinating water. In addition to the very large intermolecular interaction energies, significant nonadditivity effects can be anticipated.

(2) In the $\mathrm{Zn}$ binding site, $\mathrm{Zn}(\mathrm{II})$ is coordinated by three His and two Glu residues (Glu114 and Glu116). The occurrence of three His residues in catalytic $\mathrm{Zn}$ binding sites is not uncommon, as is the case for metallo- $\beta$-lactamase enzymes. ${ }^{3}$ While Glu or Asp can be encountered as a fourth $\mathrm{Zn}$-coordinating ligand, the simultaneous involvement of two such residues along with three histidines has, to the best of our knowledge, no precedents. Besides a structural role, the $\mathrm{Zn}$ binding site assists catalysis by properly orienting Glu116, the active-site residue involved in proton-transfer isomerization.

(3) In the $N, N$-dimethyl-2-amino-1-ethyl binding domain, the protonated terminal ethyl, dimethylammonium moiety (denoted as EDMA) undergoes electrostatic attraction from both Glu residues which coordinate $\mathrm{Zn}$ (II) in the $\mathrm{Zn}$ binding site. In addition, EDMA has cation $-\pi^{4}$ interactions with residue Trp161, which is itself in the vicinity of two other aromatic groups, Tyr104 and Trp58. Simultaneous interactions of a trior a tetramethylammonium group with Trp indole groups and carboxylate groups from Asp residues were previously observed in the recognition sites of enzymatic proteins such as acetylcholinesterase $^{5}$ and of nonenzymatic proteins such as the phosphorylcholine antibody binding site. ${ }^{6}$

NIPP can thus bind to both $\mathrm{Mg}$ (II) and $\mathrm{Zn}$ (II) binding sites, while the two sites do not interact directly between themselves.

On the basis of previous studies including crystal structures of mechanism-based inactivator complexes with the enzyme and site-directed mutagenesis results, ${ }^{2}$ a possible mechanism for isomerization of IPP into DMAPP has been proposed. In this antarafacial protonation/deprotonation mechanism, reaction is initiated by protonation of the double bond with involvement of Glu116. The proton could be given directly by this residue or could come from Tyr104 located within H bonding distance of the carboxylate group of Glu116. The possibility that the proton comes from water cannot be excluded but seems less probable, since an appropriately positioned water molecule has not been detected thus far. The tertiary carbocationic intermediate is stabilized by the metal activated carboxylate form of Glu116 and by a cation $-\pi$ interaction with the indole side chain of Trp121. The thiol moiety of Cys67, presumably in the thiolate form, assists in removing the proton from the tertiary cation. Following catalysis, the thiol proton Cys67 would then be recycled to Glu116/Tyr104. It is this mechanism hypothesis that has been adopted in the current study. An alternative in which Cys67 is the proton donor and Glu116 the proton acceptor is possible. Discrimination between both mechanisms is however out of the scope of the present study.

The magnitudes of the intermolecular interaction energies are expected to very significantly vary in the three domains considered separately, as well as upon integrating them in the complex represented in Figure 2. This provides an opportunity to evaluate the accuracy of polarizable molecular mechanics covering the range of such interactions. We will consider in succession, following the order of increasing magnitudes of their stabilization energies, the EDMA, the $\mathrm{Zn}$ and $\mathrm{Mg}$ binding sites, and then a global site, with, as well as without, the $\mathrm{Zn}$ binding site. We will consider the following issues:

EDMA Binding Site. What are the magnitudes of the individual interaction energies of EDMA with either one or both Trp161 and Trp58 indole rings, either one or both E114 and E116 carboxylate groups, and all four groups simultaneously? What are the sensitivities of the QC results to the basis sets at both uncorrelated and correlated levels? To what extent could the basis set superposition error (BSSE) affect the QC results at both levels, particularly with the largest basis set?

Zn Binding Site. What are the amplitudes of variations of the QC intermolecular interaction energies and individual contributions upon passing from a Zn(II)-His25-His32-His69 complex with all three neutral $\mathrm{Zn}$-coordinating ligands to a Zn(II)-His25-His32-His69-Glu114-Glu116 one, with two additional anionic ligands? To what extent could PMM account for these variations, both in terms of total energies and of their individual contributions?

Mg Binding Site. What are the magnitudes of intermolecular interaction energies and of their contributions concerning the binding of the monoanionic and terminal dianionic phosphate taken separately, as well as those of the trianionic diphosphate entity? In the context of PMM calculations, to what extent could diphosphate be assembled from its constitutive mono- and diphosphate fragments?

Integral Binding Site. The binding site represented in Figure 2 has a considerable buildup of anionic and cationic charges. 
The NIPP inhibitor has a net charge of -2 , namely, -3 at one extremity and +1 at the other. In addition to the two divalent cations, there are two arginine and two lysine residues, which total a charge of +4 , and three Glu and an anionic cysteinate residue, denoted as $\mathrm{Cy}^{-}$, which total a charge of -4 . The site also includes the two $\mathrm{Mg}(\mathrm{II})$-coordinating water molecules and two aromatic groups, Tyr104 and Trp161. The complex totals 148 atoms. It is one of the largest we investigated so far by QC approaches. As was the case with bacterial dihydropterin pyrophosphokinase (HPPK) ${ }^{7}$ metallo- $\beta$-lactamase (MBL) ${ }^{8}$ and phosphomannoisomerase (PMI), ${ }^{9}$ the size of the complex, the buildup of net charges, and the interplay of attractive and repulsive effects set critical challenges for PMM. With which relative accuracies could PMM still match the QMM results? Could it match the QC energy trends upon selectively removing a given residue, and what are the relative weights of polarization and charge transfer? To the best of our knowledge, there are no related systematic analyses reported in the context of any other PMM methodology than the present one, and neither possibly from semiempirical approaches.

While IDI is not a target for the development of antitumor compounds, it is noted that accumulation of IPP due to the inhibition of its rearrangement eventually results in its conversion to an ester derivative of ATP which can be pro-apoptotic against tumor cells. ${ }^{10}$ This should further raise the interest for inhibitors of IPP rearrangement. In this connection, novel lipophilic cationic bisphophonates similar to NIPP can inhibit tumor cell growth by acting as inhibitors of farnesyl diphosphate synthase and geranylgeranyl diphosphate synthases. ${ }^{11}$

\section{Procedure}

QC Computations. At the HF level, energy decompositions were done with the restricted variational space analysis (RVS). ${ }^{12}$ It decomposes the intermolecular interaction energies, denoted $\triangle E(\mathrm{RVS})$, into four separate contributions: electrostatic/ Coulomb $\left(E_{\text {Coul }}\right)$ and exchange repulsion $\left(E_{\text {exch }}\right)$ at first order and polarization $\left(E_{\mathrm{pol}}\right)$ and charge transfer $\left(E_{\mathrm{ct}}\right)$ at second order. These computations used the CEP $4-31 \mathrm{G}(2 \mathrm{~d})$ basis set. ${ }^{13}$ The basis set used on the $\mathrm{Mg}$ (II) cation is the 6-631G(2d) basis set as described in ref 14. To validate the magnitudes and trends in the complexes investigated, several calculations were also done with more extended basis sets, namely, 6-311G** and ccpVTZ. $^{15}$

The contributions of correlation to the total intermolecular interaction energies were done with the DFT procedure using the B3LYP ${ }^{16}$ and $\mathrm{PBE}^{17}$ functionals. Whenever tractable, the MP2 procedure ${ }^{18}$ was used as well, to provide a more complete representation of correlation embodying dispersion as well. The basis set superposition errors (BSSEs ${ }^{19}$ ) were computed at both the MP2 and DFT levels. These computations were done with the Gaussian 03 package. ${ }^{20}$

We have also performed DFT-D computations, in which an explicit dispersion term is added to the B3LYP functional, following the procedure due to Grimme et al., ${ }^{21}$ and implemented in Gaussian $09^{22}$ and in the 2009 version of GAMESS. ${ }^{23}$

The RVS computations were done with the GAMESS package. In its implementation, the RVS procedure removes the BSSE that involves the virtual orbitals. ${ }^{19 \mathrm{~b}}$ The reported $\triangle E(\mathrm{RVS})$ values are thus BSSE-corrected.

Polarizable Molecular Mechanics Computations. We have used the SIBFA polarizable molecular mechanics procedure. ${ }^{24}$ Within this procedure, the interfragment interaction energy is computed as a sum of five separate contributions: penetrationcorrected multipolar electrostatic, ${ }^{25} E_{\mathrm{MTP} *}$, short-range repulsion,
$E_{\mathrm{rep}}$, polarization, $E_{\mathrm{pol}}$, charge transfer, $E_{\mathrm{ct}}$, and dispersion, $E_{\mathrm{disp}}$. Details on the formulation and calibration of these contributions are given in refs 24 and 25.

IDI is assembled using the SIBFA library of fragments. In keeping with our previous studies, the distributed multipoles ${ }^{26}$ and polarizabilities ${ }^{27}$ are those derived from their HF molecular orbitals computed with the CEP 4-31G(2d) basis set. The fragments making up the NIPP inhibitor are ethyl-methylammonium, methane, monoanionic phosphate monoester $\mathrm{H}_{2} \mathrm{PO}_{3}{ }^{-}$, and dianionic phosphate $\mathrm{HPO}_{3}{ }^{2-}$. To allow for rotations around the $\mathrm{O}_{\text {est }}-\mathrm{P}$ bond, the phosphate monoester was split into a water-like fragment, $\mathrm{HO}_{\text {est }}-\mathrm{H}^{*}$, and a phosphate-like fragment, $\mathrm{H}^{*}-\mathrm{PO}_{2}{ }^{-}$. The fictitious $\mathrm{H}^{*}$ atoms bear null multipoles, and each of the $\mathrm{O}_{\text {est }}-\mathrm{H}^{*}$ and $\mathrm{H}^{*}-\mathrm{P}$ bonds bear half the multipoles and polarizabilities of the original $\mathrm{O}_{\text {est }}-\mathrm{P}$ bond.

The starting coordinates of the IDI-NIPP complex are taken from its high-resolution X-ray structure ${ }^{2}$ as deposited in the PDB file with identifier 1NFS.

Energy minimizations (EM) on the internal coordinates used the Merlin package. ${ }^{28}$ Merlin is a polyvalent minimizer, in which nongradient- and gradient-based minimizers can be activated in succession. The first category encompasses the simplex, roll, and random algorithms. The second category encompasses two quasi-Newton algorithms, namely, BFGS (Broyden-FannoGoldfarb-Davidon) and DFP (Davidon-Fletcher-Powell), and a conjugate gradient (CG) algorithm. Derivation and coding of the analytical gradients of all of the SIBFA energy contributions is not yet completed, so that the latter three algorithms could not be used with analytical gradients. These algorithms can, however, compute the gradients numerically, and they have been used as such. On the basis of several anterior tests, we found that the roll algorithm was in general more efficient than BFGS, DFP, or CG with numerical gradients, and we have resorted to it predominantly but not exclusively. This choice is done, however, at the cost of a much larger number of energy evaluations. With about 200 variables in internal coordinates, one EM run consists of 2000-4000 calculations. It can be restarted until the energy stabilizes, typically, if its variations are of $<1 \mathrm{kcal} / \mathrm{mol}$ out of $1000-2000$. A recently implemented alternative is MD using SIBFA and a simplified functional without the charge-transfer contribution and scalar, instead of anisotropic polarizabilities. It will be commented on below.

As in our previous studies on inhibitor-metalloenzyme (IM) complexes, ${ }^{7-9}$ the protein backbone is held rigid and the side chain of the residues of the recognition site and the position of the cations are relaxed. The inhibitor is fully relaxed. The assumption of a rigid protein is adopted in order to limit the number of variables for EM. It has been reconsidered in our previous paper on inhibitor binding to the Zn-metalloenzyme phosphomannoisomerase (PMI), ${ }^{9}$ in which AMBER molecular dynamics (MD) was carried out on the ligand-free PMI. MD resulted in very limited backbone relaxation and strong overlap with the starting X-ray structure. The prime objective of the present paper is to resort to high-level ab initio QC to evaluate the accuracy of PMM in the recognition site of a binuclear metallo-enzyme and its subsites, rather than a posteriori reconstitution of such a site. The optimized geometry should lend itself to such comparisons, on account of its satisfactory overlap with the X-ray structure (see below). In another vein, EM of the complex of a mercaptobenzamide inhibitor to a smaller protein, the C-terminal Zn finger of HIV-1 nucleocapsid, was carried out by relaxing all torsion angles of the protein target. $^{29}$ 
In the above-mentioned studies, solvation was accounted for by the Langlet-Claverie continuum reaction field procedure. ${ }^{30}$ Restarting EM in the presence of the continuum, while resulting in important variations of the total energy, was generally found to have only a small impact on the equilibrium geometry. Since the present study does not aim to compare the relative binding affinities of competing inhibitors, we did not resort to it.

The parameters used are those published in ref 31 . One exception relates to the oxygens of the terminal dianionic phosphate group. It was found that a representation with six $\mathrm{sp}^{3}$ lone pairs with occupation numbers of 1 was preferable to the previous one with two $\mathrm{sp}^{2}$-like lone pairs with occupation numbers of 2 and two $\pi$ lone pairs with occupation numbers of 1. This was done following test calculations on the binding to this entity of one $\mathrm{Zn}$ (II) cation or of a water molecule used as a probe (de Courcy et al., to be published). Such a choice is similar to the one originally adopted for the anionic oxygen of methoxy. ${ }^{24 b}$ The values of the effective radii (in $\AA$ ) used for penetration, repulsion, polarization, charge transfer, and dispersion are, respectively: $P_{\mathrm{W}}, 1.40 ; R_{\mathrm{W}}, 1.46 ; P_{\mathrm{W}}, 1.63 ; T_{\mathrm{W}}, 1.68$; $D_{\mathrm{W}}, 1.46$.

\section{Results and Discussion}

We denote by $\Delta E(\mathrm{SIBFA})$ and $\Delta E_{\text {tot }}(\mathrm{SIBFA})$ the SIBFA intermolecular interaction energies, respectively, without and with the dispersion energy contribution. These values are to be compared to their QC counterparts, which are respectively $\Delta E(\mathrm{HF})$ and either $\Delta E(\mathrm{MP} 2)$ or (when MP2 computations are intractable) $\Delta E(\mathrm{DFT})$. The side chains of Glu, $\mathrm{Cy}^{-}$, Lys, Arg, His, Tyr, and Trp have been modeled, respectively, by formate, methanethiolate, methylammonium, methylguanidinium, imidazole, phenol, and indole. In the IDI $\mathrm{Zn}$ binding site, all three His residues bind $\mathrm{Zn}(\mathrm{II})$ by their $\mathrm{N}_{\varepsilon}$ nitrogen. A superimposition of the energy-minimized and of the crystallographic structures is given as Supporting Information, showing a good overlap. It was done on the two metal cations, the Zn-coordinating His nitrogens, the Glu $\mathrm{C}_{\delta}$ carbons, the nitrogens of Lys and Trp side chain nitrogens, the Arg guanidinium carbon, and the NIPP nitrogen and phosphorus atoms. The rmsd is $0.54 \AA$. Following a reviewer's request, we have also considered the possible involvement of additional discrete water molecules in the binding site. We resorted to an algorithm originally designed by Daudey, Langlet, and co-workers ${ }^{32}$ to locate discrete water molecules in the vicinity of accessible polar sites, which was interfaced in the SIBFA software. We have thus included up to seven molecules in the vicinity of the NIPP end phosphate group. Three different pathways were adopted, upon relaxing the water molecules (a) without distance restraints, (b) with one water restrained to bind one anionic oxygen and another one to another anionic oxygen $\left(d_{\mathrm{H}-\mathrm{O}}=2.25 \AA\right)$, and (c) with two waters restrained to each of the two anionic oxygens. Using the newly operational MD algorithm in SIBFA, three successive MD runs on their positions and of $25 \mathrm{ps}$ for each were done. These MD runs were not pursued further on account of the shallow behavior of the energy in the last run. MD was followed by Merlin minimizations on their positions, upon also relaxing NIPP, the cations, and the side chains of the recognition site. For paths $\mathrm{b}$ and $\mathrm{c}$, a second run was done upon removing the distance restraints. We found that none of the seven added molecules had direct interactions with NIPP. These waters interacted instead at the periphery of the recognition site, and essentially with Lys21, Lys55, Arg83, and Glu135 (not shown). The overlap with the crystal structure with the sites mentioned above was similar $(0.62 \AA)$ to the $0.54 \AA \mathrm{rms}$ found in the absence of the discrete waters.

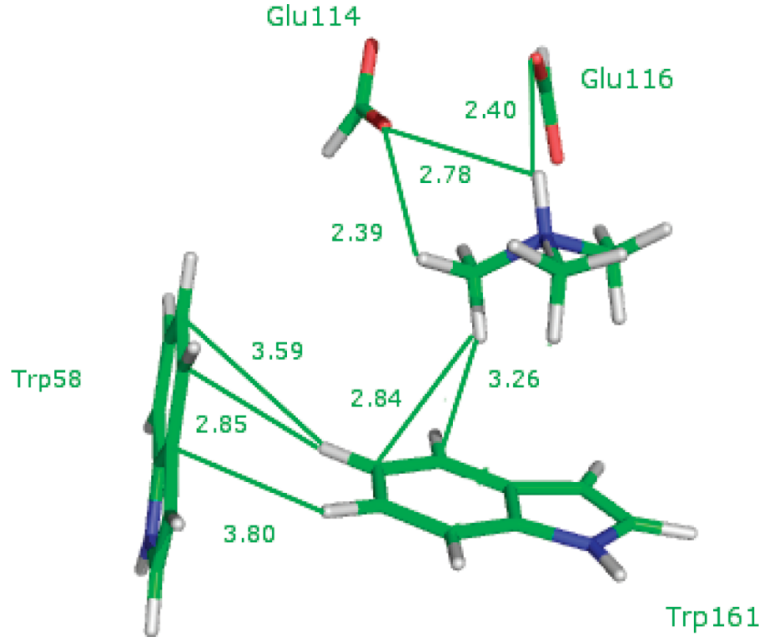

Figure 3. Representation of the EDMA binding site.

1. EDMA Binding Site (Figure 3). The results are reported in Table 1. Table 1a reports the EDMA interaction energies with the Trp side chains, and Table 1b, those with the Glu side chains, as well as its interaction energies with all four side chains, namely, Glu114, Glu116, Trp58, and Trp161.

(a) Interactions with the Trp Side Chains. The first cation $-\pi$ complexes to have been investigated in the context of PMM approaches were in a 1980 paper $^{33}$ comparing the tetra- versus monomethylammonium binding energies in the active site of a phosphorylcholine antibody which totaled up to seven side chain residues. Studies of cation $-\pi$ complexes have been subsequently reported in the context of $\mathrm{QC}^{34}$ as well as PMM. ${ }^{35}$ Table 1a shows that $\Delta E(\mathrm{SIBFA})$ can closely reproduce its $\Delta E(\mathrm{HF})$ counterparts in the four investigated complexes: the three bimolecular complexes EDMA-Trp161, EDMA-Trp58, and Trp58-Trp161 and the trimolecular EDMA-Trp161-Trp58 one. Comparison with the RVS analyses using the CEP 4-31G(2d) basis set shows that the magnitudes of the summed second-order contributions are satisfactorily reproduced as well. The values of $E_{\mathrm{ct}}(\mathrm{RVS})$ are very small. Those of $E_{\mathrm{ct}}(\mathrm{SIBFA})$ with indole as an electron donor are virtually null. When $E_{\mathrm{ct}}(\mathrm{RVS})$ is non-null, it can be compensated by a slightly larger value of $E_{\mathrm{pol}}$ in SIBFA than in HF. The numerical agreements of $\triangle E(\mathrm{SIBFA})$ with $\Delta E(\mathrm{HF})$ appear for such complexes to be better with the 6-311G** and cc-pVTZ basis sets than with the target CEP 4-31G(2d) set.

The gain in correlation following the MP2 treatment is noticeably larger with the CEP 4-31G(2d) basis set than with the $6-311 \mathrm{G}^{* *}$ and cc-pVTZ basis sets. This is most conspicuous in Trp58-Trp161, where $\delta E_{\text {corr }}$ amounts to $-7.1 \mathrm{kcal} / \mathrm{mol}$, compared to $-4.6 \mathrm{kcal} / \mathrm{mol}$ with the latter two basis sets. On the other hand, accounting for the BSSE correction results in the $\delta E_{\text {corr }}(\mathrm{MP} 2)$ values coming much closer together with all three sets. This is exemplified in the largest complex, EDMA-W161-W58, for which $\delta E_{\text {corr }}(\mathrm{MP} 2)$ amounts to -6.5 , -5.3 , and $-6.8 \mathrm{kcal} / \mathrm{mol}$ for the three respective basis sets. The corresponding value of $E_{\text {disp }}(\mathrm{SIBFA})$ is $-5.2 \mathrm{kcal} / \mathrm{mol}$. Accounting for the BSSE correction also affords a good agreement of $\Delta E_{\mathrm{tot}}(\mathrm{SIBFA})$, amounting to $-14.6 \mathrm{kcal} / \mathrm{mol}$, to $\Delta E(\mathrm{MP} 2)$, amounting to $-14.9,-13.4$, and $-14.7 \mathrm{kcal} / \mathrm{mol}$ in the three basis sets. In a recent analysis of the binding site of the $\mathrm{Zn}$ metalloenzyme alcohol dehydrogenase, BSSE was also found to bring closer together the $\Delta E(\mathrm{MP} 2)$ values computed with different basis sets, and the corresponding $\Delta E_{\text {tot }}(\mathrm{SIBFA})$ value (de Courcy et al., submitted). 
TABLE 1: Values (kcal/mol) of the QC and SIBFA Interaction Energies and Their Contributions in the EDMA Binding Site of

(a) Interactions Involving the Two Trp Side Chains

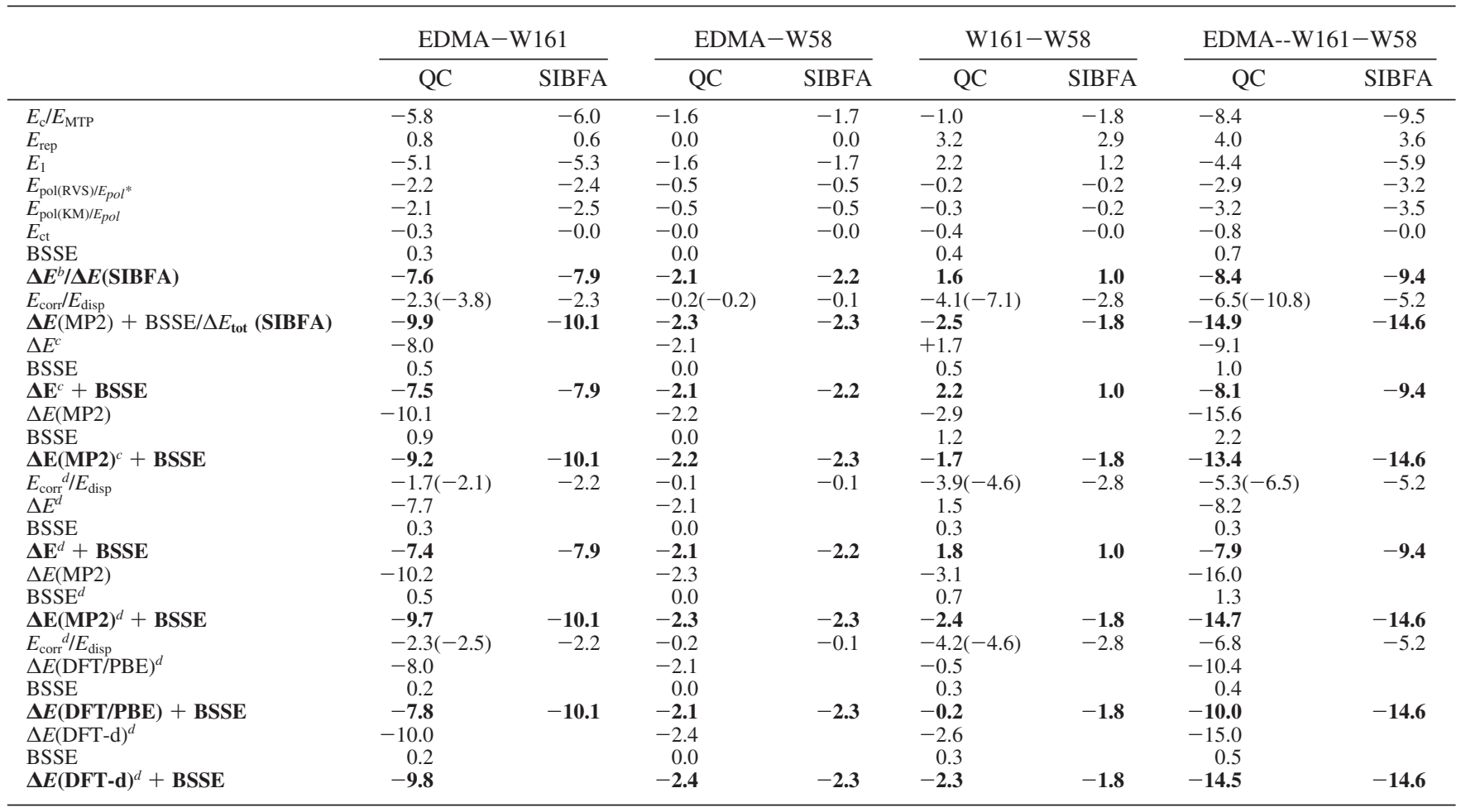

(b) Interactions Involving the Two Glu Side Chains ${ }^{e}$

\begin{tabular}{|c|c|c|c|c|c|c|c|c|c|c|}
\hline & \multicolumn{2}{|c|}{ EDMA-E114 } & \multicolumn{2}{|c|}{ EDMA-E116 } & \multicolumn{2}{|c|}{ E114-E116 } & \multicolumn{2}{|c|}{$\begin{array}{c}\text { EDMA-E114- } \\
\text { E116 }\end{array}$} & \multicolumn{2}{|c|}{$\begin{array}{c}\text { EDMA-W161- } \\
\text { W58-E114-E116 }\end{array}$} \\
\hline & QC & SIBFA & QC & SIBFA & QC & SIBFA & QC & SIBFA & QC & SIBFA \\
\hline$E_{\text {rep }}$ & 5.7 & 5.2 & 35.8 & 33.3 & 4.1 & 8.4 & 45.4 & 46.9 & 49.4 & 50.6 \\
\hline$E_{1}$ & -76.3 & -76.8 & -79.6 & -81.9 & 98.2 & 101.5 & -57.9 & -57.2 & -54.8 & -55.2 \\
\hline$E_{\mathrm{pol}(\mathrm{RVS}) / E_{\mathrm{pol}} *^{*}}$ & -5.1 & -5.3 & -12.7 & -12.5 & -5.5 & -6.9 & -24.2 & -26.0 & -25.0 & -26.6 \\
\hline$E_{\mathrm{pol}(\mathrm{KM}) / E_{p o l}}$ & -6.3 & -6.1 & -15.9 & -16.1 & -4.6 & -6.0 & -27.8 & -29.4 & -27.9 & -29.4 \\
\hline$E_{\text {corr }}^{b} / E_{\mathrm{disp}}$ & $-2.6(-4.7)$ & -2.1 & $-3.9(-8.6)$ & -5.2 & $-2.3(-6.9)$ & -2.4 & $-9.2(-18.9)$ & -9.7 & $-16.8(-31.0)$ & -15.3 \\
\hline$\Delta \boldsymbol{E}(\mathbf{M P 2})^{b}+\mathbf{B S S E} / \boldsymbol{\Delta} \boldsymbol{E}_{\text {tot }}$ & -85.9 & -85.4 & -103.2 & -105.1 & 92.8 & 93.1 & -99.3 & -98.3 & -104.5 & -101.9 \\
\hline$\Delta E^{c}$ & -86.3 & & -105.6 & & 93.6 & & -99.5 & & -97.8 & \\
\hline BSSE & 3.3 & & 5.1 & & 3.0 & & 10.8 & & 12.0 & \\
\hline$\Delta E^{c}+\mathrm{BSSE}$ & -83.0 & -83.3 & -100.5 & -99.5 & 96.6 & 95.5 & -88.7 & -88.6 & -85.8 & -86.6 \\
\hline$\Delta E(\mathrm{MP} 2)^{c}$ & -90.4 & & -112.8 & & 90.0 & & -114.3 & & -120.7 & \\
\hline BSSE & 5.4 & & 9.2 & & 4.4 & & 18.3 & & 20.7 & \\
\hline$\Delta E(\mathrm{MP} 2)^{d}$ & -85.9 & & -110.1 & -8.4 & 94.8 & & -110.4 & & -116.6 & \\
\hline BSSE & 0.3 & & 5.2 & & 2.9 & 2.4 & 10.6 & & 12.0 & \\
\hline $\boldsymbol{\Delta} \boldsymbol{E}(\mathbf{M P 2})^{d}+\mathbf{B S S E}$ & -85.6 & -85.4 & -104.9 & -105.1 & 91.9 & 93.1 & -99.8 & -98.3 & -104.6 & -101.9 \\
\hline$E_{\text {corr }}^{d}$ & -2.8 & & -5.5 & & -3.2 & & -11.2 & & -15.8 & -15.3 \\
\hline$\Delta E(\mathrm{CCSD}-\mathrm{T})^{f}$ & -88.7 & & -110.0 & & 90.0 & & -110.0 & & & \\
\hline BSSE & 3.1 & & 5.6 & & 2.9 & & 10.9 & & & \\
\hline$\Delta E(\text { CCSD-T })^{f}+$ BSSE & -85.6 & -85.6 & -104.4 & -105.1 & 92.9 & 93.1 & -99.1 & -98.3 & & \\
\hline$\Delta E(\mathrm{DFT} / \mathrm{PBE})^{d}$ & -87.8 & & -108.6 & & 94.3 & & -106.3 & & -106.4 & \\
\hline $\mathrm{BSSE}^{d}$ & 2.4 & & 3.5 & & 1.8 & & 7.5 & & 8.1 & \\
\hline$\Delta E(\mathbf{D F T} / \mathrm{PBE})+\mathbf{B S S E}^{d}$ & -85.4 & -85.6 & -105.1 & -105.1 & 92.5 & 93.1 & -98.8 & -98.3 & -98.3 & -101.9 \\
\hline$\Delta E(\text { DFT-d })^{d}$ & -88.6 & & -109.5 & & 94.1 & & -109.2 & & & \\
\hline BSSE & 2.4 & & 4.0 & & 2.3 & & 8.4 & & & \\
\hline$\Delta \boldsymbol{E}(\mathbf{D F T}-\mathbf{d})^{d}+$ BSSE & -86.2 & & -105.5 & & 91.8 & & -100.8 & & & \\
\hline
\end{tabular}

${ }^{a}$ The RVS computations are done with the CEP 4-31G(2d) basis set. Values in parentheses denote the $E_{\text {corr }}$ values uncorrected for BSSE at the MP2 level. ${ }^{b}$ CEP $4-31 \mathrm{G}(2 \mathrm{~d})$ basis set. ${ }^{c}$ 6-311G** basis set. ${ }^{d}$ cc-pVTZ basis set. ${ }^{e}$ The interactions involving both Glu and Trp side chains are given in the last column. ${ }^{f}$ cc-pVTZ(-f) basis set.

DFT/PBE computations performed with the cc-pVTZ basis set give rise to smaller interaction energies than MP2. This is particularly the case in the Trp161-Trp58 complex, for which $\Delta E(\mathrm{DFT})$ is virtually null, while it amounts to $\sim-2.0 \mathrm{kcal} /$ 
mol at the MP2 level. Computations done at the B3LYP level give rise to smaller $\Delta E(\mathrm{DFT})$ magnitudes than at the $\mathrm{PBE}$ level (unpublished). Such results are in line with earlier reports on the underestimation of stacking interactions by DFT approaches, ${ }^{36}$ while PBE represents an improvement over B3LYP in this respect. It was recently proposed to augment DFT with a damped empirical dispersion term. ${ }^{37}$ This "DFT-d" procedure has been validated on several intermolecular complexes and shown to reproduce very satisfactorily the results from $\operatorname{CCSD}(\mathrm{T})$ computations. It was of interest to test this procedure in the present context, upon resorting to the new functionalities of the G09 and GAMESS softwares. With the cc-pVTZ basis set, the values of BSSE-corrected $\triangle E$ (DFT-d) are virtually identical to the corresponding BSSE- $\triangle E(\mathrm{MP} 2)$ ones, while the BSSE errors are equal to the DFT/PBE computations.

Nonadditivity. Table 1a shows that there is a modest amount of cooperativity $(-0.2$ to $-0.4 \mathrm{kcal} / \mathrm{mol})$ found by QC and SIBFA upon comparing the values of the three bimolecular interaction energies and their contributions to those in the trimolecular complexes. Such a modest value could be due to the relatively large distances between the two aromatic rings, as translated by the very small $E_{\mathrm{pol}}$ and $E_{\mathrm{ct}}$ values in the Trp161-Trp58 complexes, limiting cooperativity. It does not prejudge on the situation in other complexes, such as in the recognition site of acetylcholinesterase, ${ }^{5}$ in which several Trp/ Phe residues bind a terminal tetramethylammonium moiety in a hydrophobic "gorge", which is being presently analyzed by parallel RVS/SIBFA analyses (de Courcy et al., to be published).

(b) Interactions with the Glu114 and Glu116 Side Chains. Uncorrelated Level. Table 1b shows that, for the EDMA-Glu114 complex, $\triangle E(\mathrm{RVS} / \mathrm{CEP} 4-31 \mathrm{G}(2 \mathrm{~d}))$ and its contributions are very closely reproduced by SIBFA. For the EDMA-Glu116 complex, a close agreement is still obtained but is due to some error compensations between first- and second-order terms. Notably, $E_{\mathrm{ct}}(\mathrm{RVS})$ amounts to $-6.0 \mathrm{kcal} / \mathrm{mol}$, whereas $E_{\mathrm{ct}}(\mathrm{SIBFA})$ has a much smaller value of $-2.1 \mathrm{kcal} / \mathrm{mol}$. The large value of $E_{\mathrm{ct}}(\mathrm{RVS})$ is due to a short distance of approach between one C-connected EDMA hydrogen and one carboxylate oxygen of Glu116, namely, $1.67 \AA$. It cannot be ascribed to $\mathrm{BSSE}$, which is limited to $1.0 \mathrm{kcal} / \mathrm{mol}$. The significantly smaller $E_{\mathrm{ct}}(\mathrm{SIBFA})$ turns out to have a limited impact on the total energies. However, it has much more severe consequences at shorter EDMA-carboxylate distances. Thus, at a distance of $1.47 \AA, E_{\mathrm{ct}}(\mathrm{RVS})$ increases in magnitude to $-12.7 \mathrm{kcal} / \mathrm{mol}$, while $E_{\mathrm{ct}}(\mathrm{SIBFA})$ is limited to $-2.7 \mathrm{kcal} / \mathrm{mol}$. On the other hand, $\triangle E(\mathrm{MP} 2)$ has a much less favorable value at this distance, namely, -94.4 instead of $-103.2 \mathrm{kcal} / \mathrm{mol}$. This would render such a structure a priori less meaningful. This shortcoming of $E_{\mathrm{ct}}(\mathrm{SIBFA})$ has precedents. In the case of H-bonded complexes, $E_{\mathrm{ct}}(\mathrm{SIBFA})$ was found to correctly reproduce $E_{\mathrm{ct}}(\mathrm{RVS})$ in all cases when the electron acceptor molecule is neutral (as with water and formamide) but to underestimate it when it is cationic, as with methylammonium or hydronium. ${ }^{25 b, 38}$ As formulated in the context of SIBFA, ${ }^{39} E_{\mathrm{ct}}$ occurs on the antibonding orbital located on the chemical bond $\mathrm{B}-\mathrm{H}$ that bears the $\mathrm{H}$ electron acceptor. The heavy atom $\mathrm{B}$ has a contribution that counteracts the transfer occurring on the $\mathrm{H}$ atom. Seeking an alternative formulation of the coefficient $F_{\mathrm{B}}$ (formula 25 from ref $39 \mathrm{~b}$ ) upon which such a contribution depends, and in order to reduce it, could possibly restore to $E_{\mathrm{ct}}$ a proper magnitude. This will be considered in future studies but is however beyond the scope of the present work.

Table $1 \mathrm{~b}$ shows that, following the BSSE correction, the 6-311G** and cc-pVTZ basis sets give $\Delta E$ values that are very close to the CEP 4-31G(2d) ones. This is the case for the bimolecular complexes as well as for the tri- and pentamolecular complexes. Upon passing from the three bimolecular complexes to the trimolecular one, a small cooperativity of $E_{\mathrm{pol}}$ is observed with the CEP 4-31G(2d) basis set. Thus, $E_{\mathrm{pol}}$ amounts to -27.8 in the trimolecular complex, while its summed value in the three bimolecular complexes is $-26.8 \mathrm{kcal} / \mathrm{mol}$. Such cooperativities translate the fact that the two carboxylates bind EDMA from the same side, rather than from opposite sides. Their polarizing fields thus sum up instead of opposing one another. $E_{\text {pol }}$ (SIBFA) amounts to -29.4 in the trimolecular complex, and its sum in the three bimolecular complexes amounts to $-28.2 \mathrm{kcal} / \mathrm{mol}$. It is thus cooperative by a very similar amount as $E_{\mathrm{pol}}(\mathrm{RVS})$, namely, -1.2 as compared to -1 . $\mathrm{kcal} / \mathrm{mol}$. $E_{\mathrm{ct}}(\mathrm{SIBFA})$, despite its small value, is slightly anticooperative $(0.5 \mathrm{kcal} / \mathrm{mol})$, while $E_{\mathrm{ct}}(\mathrm{RVS})$ has virtually no anticooperative effects. It actually displays a small $(-0.8 \mathrm{kcal} / \mathrm{mol}$ out of 13$)$ cooperative character at the shorter $\mathrm{O}^{-}-\mathrm{H}(\mathrm{C})$ distance of $1.47 \AA$.

Correlated Level. Prior to the BSSE correction, $\delta E_{\text {corr }}(\mathrm{MP} 2)$ has the largest magnitudes along the sequence CEP 4-31G(2d) $>$ cc-pVTZ $>6-311 \mathrm{G}^{* *}$. It is seen that, even with the cc-pVTZ basis set, the BSSE correction is significant, amounting to 4.9 $\mathrm{kcal} / \mathrm{mol}$ out of 16 for the trimer. Following the BSSE correction, the $\delta E_{\text {corr }}(\mathrm{MP} 2)$ values come closer together in all three basis sets. Rather unexpectedly, it is the cc-pVTZ basis set that generally gives rise to the largest $\delta E_{\text {corr }}(\mathrm{MP} 2)$ values, while the CEP 4-31G(2d) ones are intermediate between the cc-pVTZ and $6-311 \mathrm{G}^{* *}$ sets. The values of $E_{\text {disp }}(\mathrm{SIBFA})$ are consistently smaller than the $\delta E_{\text {corr }}(\mathrm{MP} 2)$ ones, and are much closer to them when the BSSE correction is taken into account. This can be exemplified in the largest complex, EDMA-Trp161Trp58-Glu114-Glu116. $\delta E_{\text {corr }}(\mathrm{MP} 2)$ has the values -16.8 , -13.2 , and $-15.8 \mathrm{kcal} / \mathrm{mol}$ with the three respective basis sets, while $E_{\text {disp }}(\mathrm{SIBFA})$ amounts to $-15.3 \mathrm{kcal} / \mathrm{mol}$. Since prior to correlation $\triangle E$ (SIBFA) had close agreements with the BSSEcorrected $\triangle E(\mathrm{HF})$ values with the three basis sets, this applies equally to the total interaction values as well. $\Delta E(\mathrm{MP} 2)$ amounts to $-104.5,-101.9$, and $-104.6 \mathrm{kcal} / \mathrm{mol}$, while $\Delta E_{\text {tot }}(\mathrm{SIBFA})$ amounts to $-101.9 \mathrm{kcal} / \mathrm{mol}$. It has to be recalled again, however, that such an agreement downgrades at shorter EDMA distances of approach owing to the underestimation of $E_{\mathrm{ct}}(\mathrm{RVS})$. We have in addition performed $\operatorname{CCSD}(\mathrm{T})$ computations on the three EDMA-formate complexes, using the cc-pVTZ(-f) basis set. The values of the intermolecular interaction energies are found to be very close to the corresponding MP2 ones with the cc-pVTZ basis set.

DFT computations give rise to much closer agreements with the MP2 ones regarding the EDMA complexes with Glu114 and Glu116, as compared to the indole complexes, while the BSSE corrections are smaller. Not unexpectedly on the other hand, the agreement downgrades in the largest complex encompassing the two indole groups. The BSSE-corrected values of $\Delta E(D F T-d)$ are again very close $(\leq 1 \mathrm{kcal} / \mathrm{mol}$ out of $100)$ to the corresponding $\Delta E(\mathrm{MP} 2)$ values.

For all EDMA complexes, the close agreements of DFT-d calculations with BSSE-corrected MP2 values suggest that this procedure could be very suitable for future benchmarks of SIBFA on large molecular complexes. Further work is necessary, however, concerning the polyligated complexes of divalent metal cations, and the dependencies upon the DFT functionals and basis sets. These will be reported in a separate study.

2. Zn Binding Site (Figure 4). The results are given in Table 2. The first two columns give the QC and SIBFA interaction energies for the $\mathrm{Zn}$ complex with the three His side chains, and 


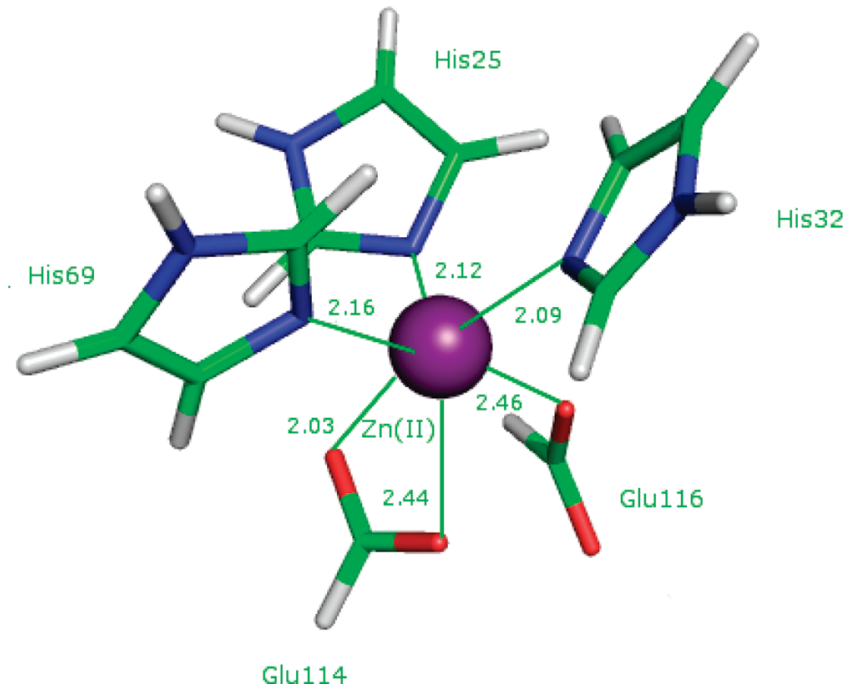

Figure 4. Representation of the $\mathrm{Zn}$ binding site.

the last two ones with the additional Glu114 and Glu116 side chains. The first complex was previously examined by parallel QC and SIBFA computations ${ }^{31,40 a}$ but in a geometry resulting from energy minimization on the $\mathrm{Zn}(\mathrm{II})$-(imidazole) ${ }_{3}$ complex. The computations reported here are single-point computations on a geometry extracted from EM on the complete IDI-NIPP complex, in which $\mathrm{Zn}$ (II) is pentacoordinated. At the uncorrelated level, $\Delta E(\mathrm{SIBFA})$ has a close agreement to $\Delta E(\mathrm{RVS})$, the relative error amounting to $<3 \%$. Such an agreement can however partly stem from small error compensations between first- and second-order contributions, with $E_{1}$ (SIBFA) being larger in magnitude than $E_{1}(\mathrm{RVS})$ and $E_{2}$ (SIBFA) being correspondingly smaller. After correction for BSSE, $\triangle E(\mathrm{cc}-$ $\mathrm{pVT}(-\mathrm{f}))$ has closer values to $\Delta E(\mathrm{CEP} 4-31 \mathrm{G}(2 \mathrm{~d}))$ than to $\Delta E(6-$ $\left.311 \mathrm{G}^{* *}\right)$. At the correlated level, $\delta E_{\text {corr }}$ is smaller in magnitude with the $6-311 \mathrm{G}^{* *}$ basis set than with the CEP 4-31G(2d) one, even after subtracting the BSSE at the MP2 level. Such smaller $\delta E_{\text {corr }}$ magnitudes with the 6-311G** set are consistent with the results from Table 1 and those of our recent study which bore on the active site of the Zn-metalloenzyme alcohol dehydrogenase. ${ }^{41} \delta E_{\text {corr }}$ (cc-pVTZ(-f)) also undergoes significant reductions in its magnitude following correction for BSSE, but such reductions remain smaller than with the two other basis sets. These reductions amount to -3.5 and $-11.3 \mathrm{kcal} / \mathrm{mol}$ without and with the carboxylate anions. The corresponding values are -18.7 and $-42.4 \mathrm{kcal} / \mathrm{mol}$ with the CEP $4-31 \mathrm{G}(2 \mathrm{~d})$ basis and -5.7 and $-15.9 \mathrm{kcal} / \mathrm{mol}$ with the $6-311 \mathrm{G} * *$ basis set. As a consequence, $\delta E_{\text {corr }}(\mathrm{MP} 2)$ is the largest with the ccpVTZ(-f) basis set. The fact that $E_{\text {disp }}(\mathrm{SIBFA})$ has larger values than BSSE-corrected $\delta E_{\text {corr }}$ rather than being close to it as in the EDMA complexes most likely stems from the nonadditive behavior of $\delta E_{\text {corr }}$ in polycoordinated $\mathrm{Zn}$ (II) complexes, as analyzed in refs 40 and 41 , while $E_{\text {disp }}$ in its present formulation is additive. As a consequence of the present overestimation of BSSE-corrected $\delta E_{\text {corr }}$ by $E_{\text {disp }}(\mathrm{SIBFA}), \Delta E_{\text {tot }}(\mathrm{SIBFA})$ overestimates $\triangle E(\mathrm{MP} 2)$. The least overestimation is with respect to the cc-pVTZ basis set. Thus, with the two carboxylates, $\Delta E_{\text {tot }}(\mathrm{SIBFA})$ amounts to $-660.4 \mathrm{kcal} / \mathrm{mol}$, as compared to $-619.8,-607.9$, and $-630.4 \mathrm{kcal} / \mathrm{mol}$ with CEP 4-31G(2d), 6-311G**, and cc-pVTZ(-f), respectively.

We have also evaluated whether, due to conjugation, acetate would not be a better representative of the end side chain of aspartate and Glu residues than formate. Thus, similar QC and SIBFA computations were carried out with this group instead of formate. The corresponding results are given in brackets in Table 2. They do not show major changes in the binding energies and their contributions. However, due to conjugation, it was necessary to use for SIBFA the multipoles and polarizabilities of acetate, instead of assembling those of formate and methane, as the latter procedure resulted in a lesser agreement. This will be considered for future studies.

3. Mg(II) Binding Site (Figure 5, Table 3). In addition to the NIPP phosphate groups, $\mathrm{Mg}$ (II) is coordinated by the Glu116 side chain, the formamide moiety of the $\mathrm{Cy}^{-}{ }_{67}$ main chain, and two water molecules. We have investigated the separate binding energies to this site of the central and terminal NIPP phosphate groups, which bear a monoanionic and a dianionic charge, respectively, as well as with the trianionic diphosphate entity. The latter was constructed either (i) as a single integral and rigid fragment with its conformation-dependent multipoles and polarizabilities or (ii) assembled as the juxtaposition of two fragments: monoanionic phosphate monoester $\mathrm{H}_{2} \mathrm{PO}_{3}{ }^{-}$and dianionic phosphate $\mathrm{HPO}_{3}{ }^{2-}$. In such a case, the interaction between the two fragments is computed simultaneously with those with the other fragments making up the complex. The total intermolecular interaction energy is then derived after subtraction of this interfragment interaction in the absence of the rest of the complex. Such a procedure was previously adopted to compute the conformation-dependent $\mathrm{Zn}$ (II) interaction energies of glycine and the glycine zwitterion, ${ }^{42}$ mercaptocarboxylates, ${ }^{43}$ and the pyrophosphate anion, the end group of ATP bearing a total charge of $-4,{ }^{7}$ as well as the complexes of $\mathrm{Cu}(\mathrm{I})$ and $\mathrm{Cu}(\mathrm{II})$ with flexible ligands. ${ }^{44}$ It enables one to compute simultaneously and consistently both inter- and intramolecular polarization and charge-transfer interactions, which is necessary due to the very strong nonadditivities of these contributions. It is recalled that, owing to the conformation dependencies of the multipoles, ${ }^{45}$ procedure ii cannot be used to perform torsions around the phosphate ester bonds connecting the two phosphates. Owing to the presence of the highly polarizable nature of the phosphate entities, we resorted for the QC computations, along with the CEP 4-31G(2d) basis set, to the $6-311 \mathrm{G}^{* *}, 6-311++\mathrm{G}(3 \mathrm{df}, 2 \mathrm{pd})$, and cc-pVTZ(-f) basis sets. We observe that the two larger basis sets, namely, 6-311++ G(3df,2pd) and cc-pVTZ(-f), have better agreements with the CEP $4-31 G(2 d)$ results than with the $6-311 G^{* *}$ ones. While the corresponding $E_{1}$ values are closer to the CEP 4-31G(2d) ones than to the 6-311G** ones, we observe, unexpectedly, that the values of $E_{\mathrm{pol}}$ are smaller (in spite of the larger polarizabilities) while the $E_{\mathrm{ct}}$ values are concomitantly larger in magnitude. $\delta E_{\text {corr }}$ has smaller magnitudes with the $6-311 \mathrm{G}^{* *}$ basis set. It further decreases with the $6-311++\mathrm{G}(3 \mathrm{df}, 2 \mathrm{pd})$ to increase slightly again with the cc-pVTZ(-f) set. For the monoanionic phosphate complex a (Table 3a), $\Delta E$ (SIBFA) reproduces very closely the $\Delta E(\mathrm{RVS} / \mathrm{CEP} 4-31 \mathrm{G}(2 \mathrm{~d}))$ target values, although the errors $(<2 \mathrm{kcal} / \mathrm{mol}$ out of 550) are smaller than those of the individual contributions, with the overestimation of $E_{\mathrm{c}}$ by $E_{\mathrm{MTP}} *$ being compensated by a concomitant underestimation of $E_{\mathrm{pol}}(\mathrm{RVS})$ by $E_{\mathrm{pol}} * \Delta E(\mathrm{SIBFA})$ has a closer agreement with the 6-311++G(3df,2pd) and cc-pVTZ(-f) $\Delta E$ values than with the $6-311 \mathrm{G}^{* *}$ one. For the dianionic phosphate complex b (Table $3 \mathrm{~b}), \Delta E($ SIBFA) overestimates $\Delta E(\mathrm{RVS} / \mathrm{CEP}$ $4-31 \mathrm{G}(2 \mathrm{~d})$ ) by $10.6 \mathrm{kcal} / \mathrm{mol}$ out of 670 , i.e., a relative error of $2 \% . E_{1}(\mathrm{SIBFA})$ is larger in magnitude than $E_{1}(\mathrm{RVS})$ by $24 \mathrm{kcal} /$ mol, due to both $E_{\mathrm{MTP}} *$ and $E_{\text {rep }}$. Half of this difference is compensated by corresponding underestimations of $E_{\mathrm{ct}}(\mathrm{RVS})$ and $E_{\mathrm{pol}}(\mathrm{RVS}) . E_{\mathrm{pol}}(\mathrm{QC})$ and $E_{\mathrm{pol}}(\mathrm{SIBFA})$ have larger values in the monoanionic phosphate complex than in the dianionic one. 
TABLE 2: Values (kcal/mol) of the QC and SIBFA Interaction Energies and Their Contributions in the Zn(II) Binding Site of IDI $^{a}$

\begin{tabular}{|c|c|c|c|c|}
\hline & \multicolumn{2}{|c|}{$\mathrm{Zn}(\mathrm{II})-\mathrm{H} 25-\mathrm{H} 32-\mathrm{H} 69$} & \multicolumn{2}{|c|}{$\mathrm{Zn}(\mathrm{II})-\mathrm{H} 25-\mathrm{H} 32-\mathrm{H} 69-\mathrm{E} 114-\mathrm{E} 116$} \\
\hline & RVS & SIBFA & RVS & SIBFA \\
\hline$E_{\mathrm{c}} / E_{\mathrm{MTP}}$ & -244.7 & -257.4 & $-652.1[-652.2]$ & $-683.9[-685.8]$ \\
\hline$E_{1}$ & -161.2 & -176.0 & $-490.2[-484.4]$ & $-513.7[-510.8]$ \\
\hline$E_{\mathrm{pol}(\mathrm{RVS}) / E_{\mathrm{pol}} *}$ & -140.5 & -131.1 & $-101.6[-104.8]$ & $-85.8[-88.5]$ \\
\hline$E_{\mathrm{pol}(\mathrm{KM}) / E_{\mathrm{pol}}}$ & & -108.1 & & $-64.2[-66.4]$ \\
\hline$E_{\mathrm{ct}}$ & -31.2 & -26.9 & $-28.6[-29.4]$ & $-30.1[-30.8]$ \\
\hline$E_{\text {corr }} / E_{\text {disp }}$ & $-20.1(-38.8)$ & -29.0 & $-24.7(-67.1)[-28.6(-73.6)]$ & $-52.9[-57.8]$ \\
\hline$\Delta E(\mathrm{MP} 2)$ & -341.8 & & $-669.6[-672.8]$ & \\
\hline$\Delta E(\mathrm{MP2})+\mathrm{BSSE} / \Delta \boldsymbol{E}_{\mathrm{tot}}^{b}$ & -325.0 & -340.0 & $-619.8[-620.6]$ & $-660.9[-665.7]$ \\
\hline$\Delta E^{c}$ & -300.1 & & -606.7 & \\
\hline BSSE & 6.7 & & 21.1 & \\
\hline$\Delta \boldsymbol{E}^{c}+\mathbf{B S S E}$ & -293.9 & -311.0 & -585.6 & -608.0 \\
\hline$\Delta E^{d}$ & -304.7 & & -600.9 & \\
\hline $\boldsymbol{\Delta} \boldsymbol{E}^{d}+\mathbf{B S S E}$ & -302.5 & -311.0 & -590.7 & -608.0 \\
\hline$\Delta E(\mathrm{MP} 2)^{d}$ & -335.9 & & -651.9 & \\
\hline $\boldsymbol{\Delta E}(\mathbf{M P 2})^{d}+$ BSSE & -330.2 & -340.0 & -630.4 & -660.9 \\
\hline$E_{\text {corr }}$ & $-27.7(-31.2)$ & -29.0 & $-39.7(-51.0)$ & -52.9 \\
\hline$\Delta E(\mathrm{DFT} / \mathrm{PBE})^{d}$ & -333.0 & & -645.8 & \\
\hline $\boldsymbol{\Delta} \boldsymbol{E}(\mathbf{D F T})+\mathbf{B S S E}^{d}$ & -323.6 & & -635.9 & \\
\hline
\end{tabular}

${ }^{a}$ With the CEP 4-31G(2d) basis set, values in brackets are those computed with acetate instead of formate to represent the end side chain of the Glu residues. The values of $E_{\text {corr }}$ in parentheses are those uncorrected for BSSE. ${ }^{b}$ CEP $4-31 G(2 d)$ basis set. ${ }^{c} 6-311 G^{* *}$ basis set. ${ }^{d}$ cc-pVTZ(-f) basis set.

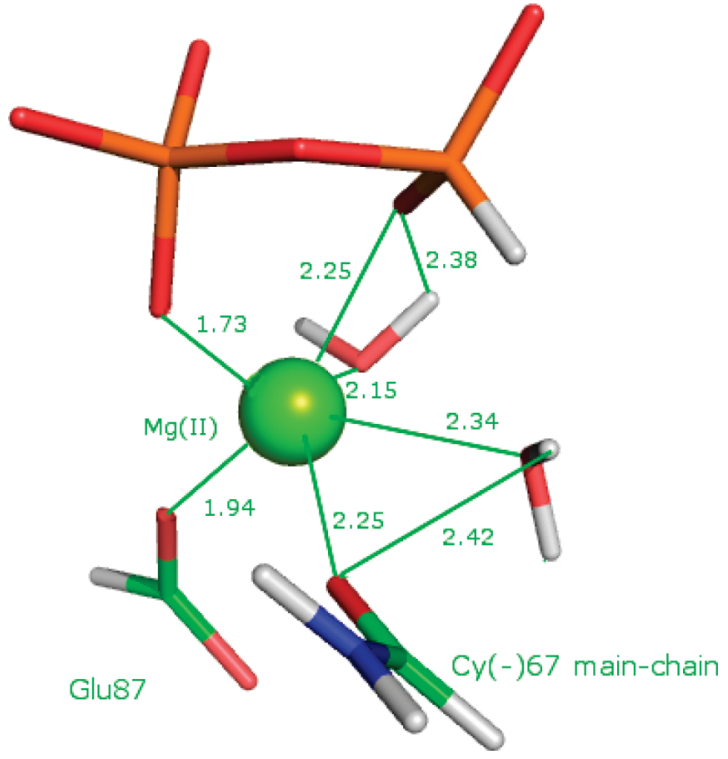

Figure 5. Representation of the Mg binding site.

This indicates that, in the latter complex, the stronger shielding of the dicationic $\mathrm{Mg}(\mathrm{II})$ charge by the dianionic phosphate overcomes the increase of its polarizability into impacting the $E_{\text {pol }}$ trends.

When in complex c (Table 3c) trianionic phosphate is built as a single rigid fragment, $\triangle E(\mathrm{SIBFA})$ overestimates $\Delta E(\mathrm{RVS} /$ CEP 4-31G(2d)) by an increased amount, namely, $28 \mathrm{kcal} / \mathrm{mol}$ out of 787 , i.e., a relative error of $3.5 \%$. However, when it is built using procedure ii, a significantly improved agreement is found, the error being $9 \mathrm{kcal} / \mathrm{mol}$ out of 780 , i.e., $<1.5 \%$. Consistent with our previous findings, ${ }^{7,42,43}$ matching the $\Delta E(\mathrm{QC})$ values can occur in spite of the imbalance of first- and second-order contributions, with $E_{1}$ being larger in magnitude than $E_{1}(\mathrm{RVS})$ and $E_{\mathrm{pol}}(\mathrm{SIBFA})$ being smaller than $E_{\mathrm{pol}}(\mathrm{QC})$. The smaller $E_{\mathrm{pol}}$ values are due to the fact that each phosphate group undergoes the negative field exerted by the other, which strongly opposes the field due to the $\mathrm{Mg}$ (II) binding site, itself dominated by the dication charge. As mentioned in our previous studies, upon using procedure $i$, such interfragment polarizations have taken place during the SCF procedure and are built into the actual triphosphate wave function and the multipoles and polarizabilities derived from it. An unexpected finding on the other hand is the fact that the larger $E_{1}$ (SIBFA) values are due to $E_{\text {rep }}$ and not to $E_{\mathrm{MTP} *}$. $E_{\text {rep }}$ has dependencies upon the monopole distributions on the atoms, and this may reflect the greater impact of such dependencies than those of $E_{\mathrm{MTP}} *$ in such a case. There is one caveat in this connection. Regarding the complexes of both dianionic and trianionic phosphates using procedure i, a much better agreement of $E_{\text {rep }}$ (SIBFA) with its RVS counterpart is obtained by simply increasing the value of the effective radius of the dianionic oxygens, from 1.45 to 1.60 $\AA$. However, this would be inconsistent with the calibration adopted in other ongoing studies on inhibitors having a dianionic phosphate moiety. The present calibration enables a much better reproduction of QC values upon resorting to procedure ii which alone could be used to model flexible diphosphates. Nevertheless, a more detailed investigation of the electron distribution around the dianionic phosphate group remains necessary, as well as of the manner in which it is affected when it is conjugated to another phosphate group as in di- or pyro-phosphates, or integrated into a larger entity, as found in some $\mathrm{Zn}$-metalloenzyme inhibitors ${ }^{46}$ or in phosphorylated residues. Studies along these lines using the ELF procedure ${ }^{47}$ will be reported separately. $E_{\text {disp }}(\mathrm{SIBFA})$ has smaller magnitudes than $\delta E_{\text {corr }}(\mathrm{CEP} 4-31 \mathrm{G}(2 \mathrm{~d}))$ and $\delta E_{\text {corr }}\left(6-311 \mathrm{G}^{* *}\right)$. It is recalled that, in the present calibra- 
TABLE 3: Values (kcal/mol) of the Intermolecular Interaction Energies in the Mg Binding Site Encompassing a Formamide Group to Model the $\mathrm{Cy}^{-}{ }_{67}$ Main Chain, Glu ${ }_{116}$, and Waters Wat ${ }_{1}$ and Wat ${ }^{a}$

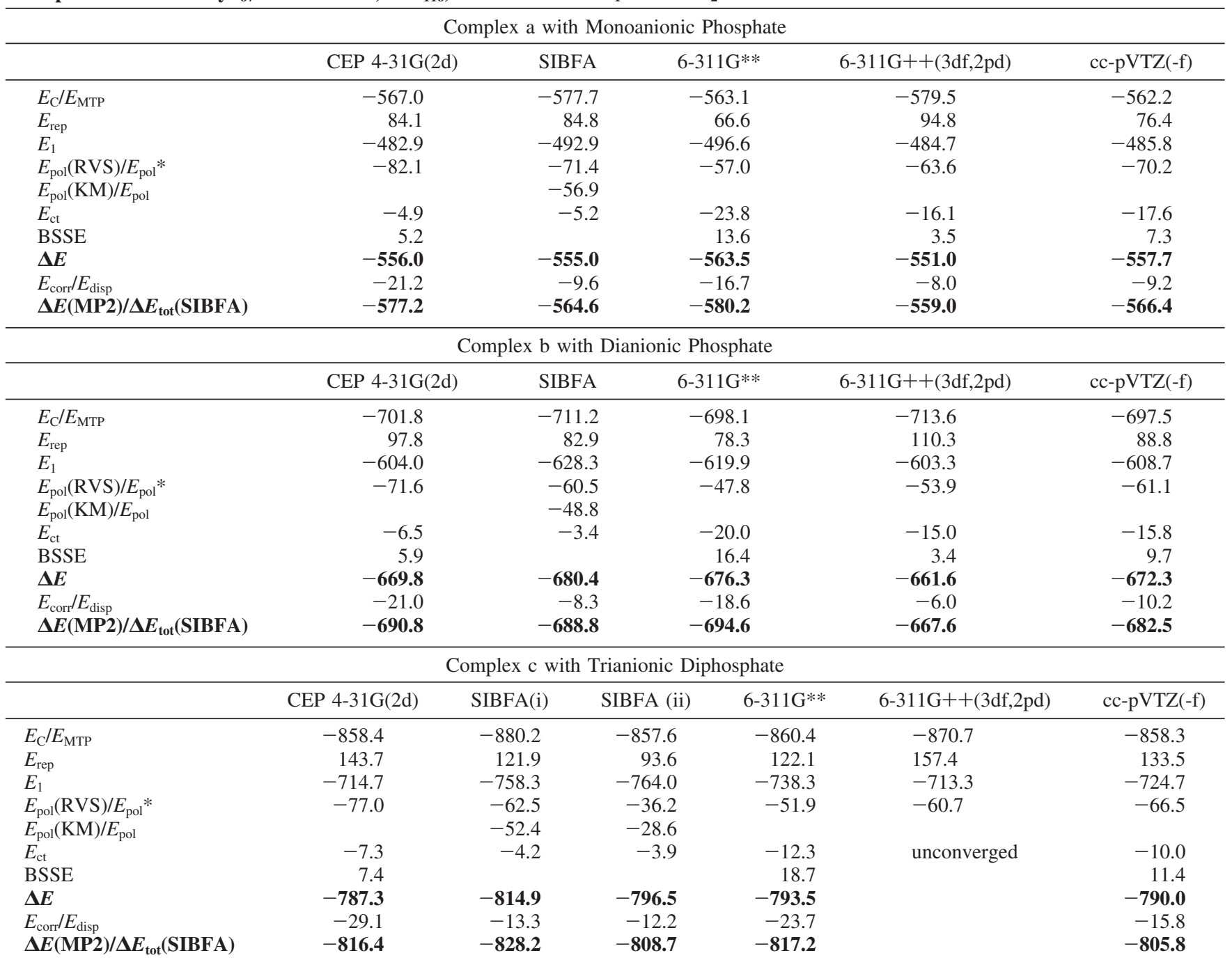

${ }^{a}$ We have considered separately the contributions to $\mathrm{Mg}(\mathrm{II})$ binding of (a) the monoanionic phosphate $\mathrm{P}_{1}$ and (b) the dianionic phosphate $\mathrm{P}_{2}$. A diphosphate entity was next considered in which $\mathrm{P}_{1}$ and $\mathrm{P}_{2}$ are connected by an ester oxygen (c). In the SIBFA calculations, it is either (i) built as one single rigid fragment (second column of results) or (ii) assembled by mutually interacting $\mathrm{H}_{2} \mathrm{PO}_{2}{ }^{-}, \mathrm{HOH}$, and $\mathrm{HPO}_{3}{ }^{2-}$ fragments (third column of results).

tion, the contribution of the $\mathrm{Mg}(\mathrm{II})$ cation to $E_{\mathrm{disp}}(\mathrm{SIBFA})$ is null. ${ }^{48}$ This choice was grounded on the basis of earlier MP2 computations of $\mathrm{Mg}$ (II) monoligated complexes with the CEP 4-31G(2d) set, for which $\delta E_{\text {corr }}(\mathrm{MP} 2)$ had very small magnitudes. ${ }^{14}$ As such, $E_{\text {disp }}(\mathrm{SIBFA})$ has much closer values to $\delta E_{\mathrm{corr}}$ from the two largest basis sets, and this is also reflected in the total interaction energies. For the trianionic phosphate complex, procedure ii enables a much better agreement of $\Delta E_{\mathrm{tot}}(\mathrm{SIBFA})$ with $\Delta E(\mathrm{MP} 2 / 6-311 \mathrm{G}++(3 \mathrm{df}, 2 \mathrm{pd}))$ and $\Delta E(\mathrm{MP} 2 / \mathrm{cc}-\mathrm{pVTZ}$ (-f)) than procedure $i$.

4. NIPP Binding Site. Consideration of the NIPP binding site is an important and instructive benchmark for PMM approaches. As in our HPPK study, ${ }^{7}$ we quantify the effects on the interaction energies of removal of some selected residues from the site: Trp161, Tyr104, and $\mathrm{Cy}^{-}{ }_{67}$. We also removed the two $\mathrm{Mg}(\mathrm{II})$-coordinating water molecules. This approach allows us to quantify how well PMM responds to such "mutations" as compared to QC. The results are reported in Table 4.

(a) Energy Values in the Absence of the Zn Binding Site. $\triangle E(\mathrm{SIBFA})$ underestimates $\Delta E(\mathrm{HF} / \mathrm{CEP} 4-31 \mathrm{G}(2 \mathrm{~d}))$ by values in the range $22.5-26 \mathrm{kcal} / \mathrm{mol}$ out of 950 , representing relative errors of $\sim 3 \%$. This difference should be reduced upon including the BSSE. A lower bound could be provided by its value in the $\mathrm{Mg}(\mathrm{II})$ site augmented with the side chains of Lys21, Arg51, Lys55, and Arg83, namely, 12 kcal/mol (unpublished data). This would thus reduce such a difference to $11-14 \mathrm{kcal} / \mathrm{mol}$ out of 900 . The $6-311 \mathrm{G}^{* *} \Delta E(\mathrm{HF})$ values are by $2 \%$ larger in magnitude than the CEP 4-31G(2d) ones, so that the $\Delta E(\mathrm{SIBFA})$ values differ by $40-46 \mathrm{kcal} / \mathrm{mol}$ from them. Calculations of the entire BSSE were performed using the G03 software. Its values are in the range $29-40 \mathrm{kcal} / \mathrm{mol}$ for the five complexes. The $\triangle E(\mathrm{SIBFA})$ values are seen to differ from the BSSE-corrected $\Delta E\left(\mathrm{HF} / 6-311 \mathrm{G}^{* *}\right)$ ones by much smaller differences, namely, $<8 \mathrm{kcal} / \mathrm{mol}$. This represents relative errors less than $1 \%$.

$\Delta E(\mathrm{HF} / \mathrm{cc}-\mathrm{pVTZ}(-\mathrm{f}))$ has values intermediate between CEP 4-31G(2d) and 6-311G** basis sets. This is fully consistent with the results found in the individual binding sites. The BSSEcorrected $\Delta E(\mathrm{HF} / \mathrm{cc}-\mathrm{pVTZ}(-\mathrm{f}))$ values are very close to those obtained with the $6-311 \mathrm{G}^{* *}$ basis set. The fact that $\Delta E$ (SIBFA) can closely reproduce the BSSE-corrected $\triangle E(\mathrm{HF})$ calculated with both extended basis sets is worth mentioning, considering the method was calibrated on the CEP 4-31G(2d) set. These 
TABLE 4: Values $(\mathrm{kcal} / \mathrm{mol})$ of the Intermolecular Interaction Energies in the NIPP Binding Site ${ }^{a}$

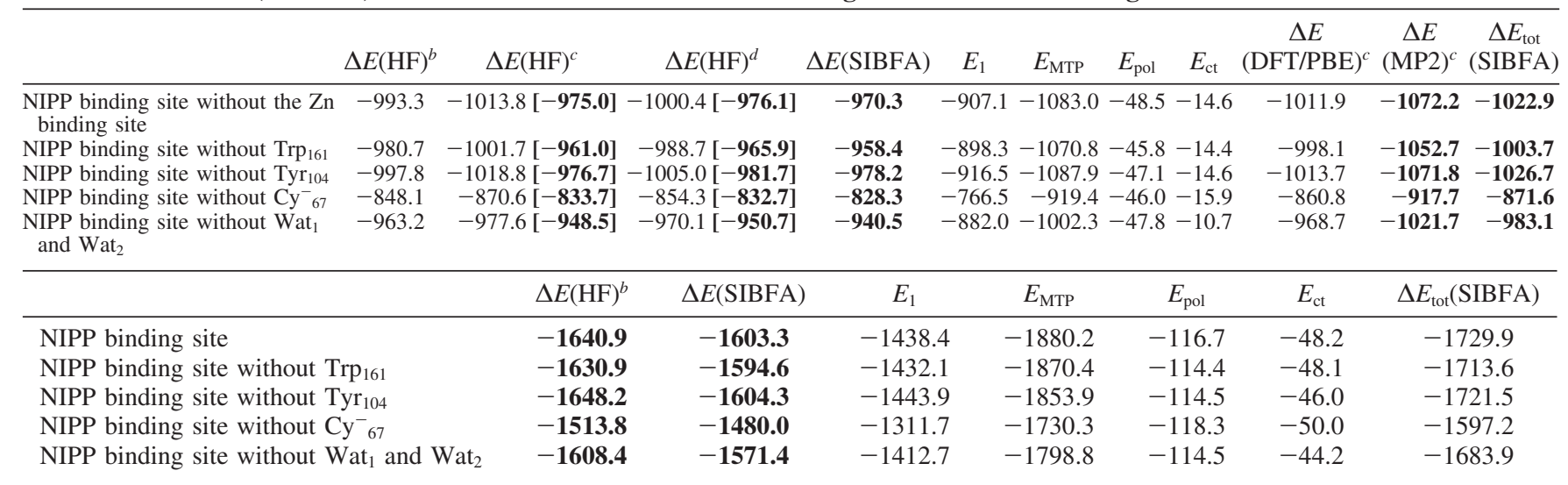

${ }^{a}$ At the HF level, three Gaussian basis sets are used: CEP 4-31G(2d), 6-311G**, and cc-pVTZ(-f). The bracketed values are the BSSE-corrected ones. The computations are also reported following removal of $\mathrm{Trp}_{161}, \mathrm{Tyr}_{104}, \mathrm{Cy}^{-}{ }_{67}$, or NIPP-bound water molecules Wat ${ }_{1}$ and Wat $2 .{ }^{b}$ CEP $4-31 \mathrm{G}^{* *}$ basis set. ${ }^{c}$ 6-311G** basis set. ${ }^{d}$ cc-pVTZ(-f) basis set.

a)

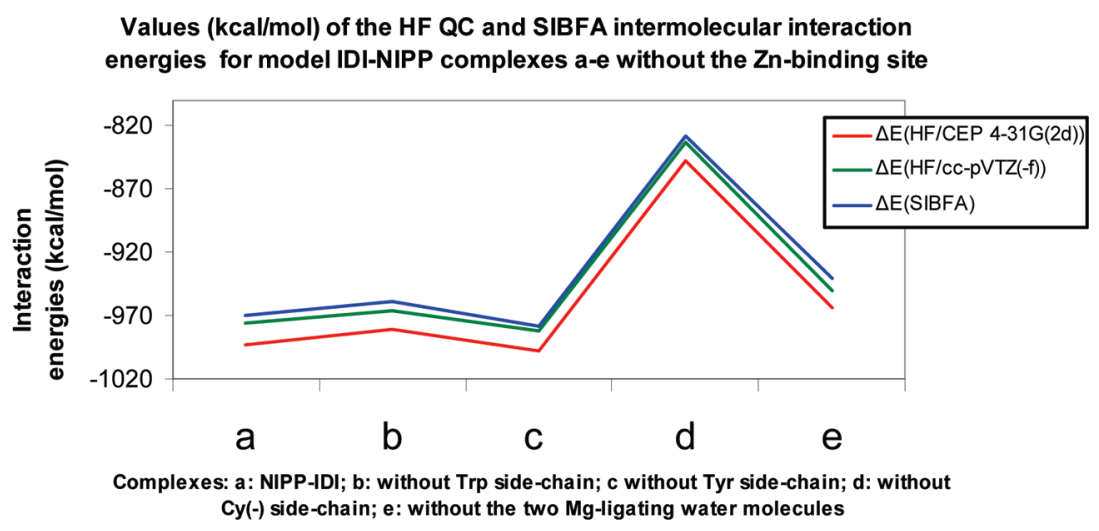

b) Values (kcal/mol) of the QC and SIBFA intermolecular interaction energies

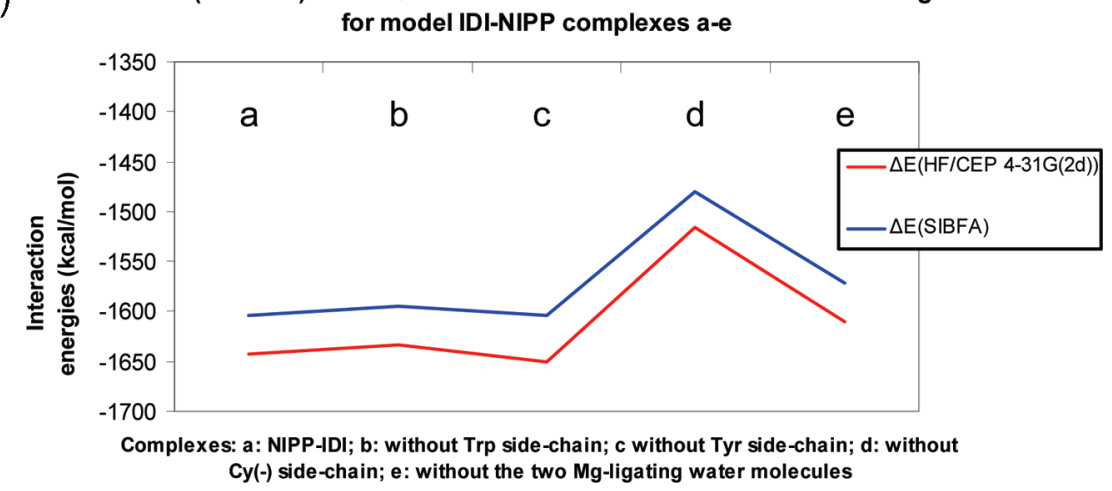

Figure 6. Compared evolutions of $\Delta E(\mathrm{HF})$ and of $\Delta E$ (SIBFA) without dispersion upon removal of individual residues (Tyr104, Trp161, Cy $\left.{ }^{-}{ }_{67}\right)$ or $\mathrm{Mg}(\mathrm{II})$-coordinating water molecules. (a) In the absence of the $\mathrm{Zn}$ binding site. The red and green curves relate to the HF/CEP 4-31G(2d) and BSSE-corrected HF/cc-pVTZ(-f) results, respectively. The blue curve relates to the SIBFA curve. (b) In the presence of the Zn binding site. The red and blue curves relate to the HF/CEP 4-31G(2d) and SIBFA results, respectively.

close numerical agreements occur in spite of the limitations that were analyzed on the individual sites. We have reported in Figure 6a the evolutions of $\triangle E(\mathrm{HF} / \mathrm{CEP} 4-31 \mathrm{G}(2 \mathrm{~d}))$, of BSSEcorrected $\Delta E(\mathrm{HF} / \mathrm{cc}-\mathrm{pVTZ}(-\mathrm{f})$, and of $\Delta E(\mathrm{SIBFA})$ in the five considered complexes.

At the correlated level, $\Delta E\left(\mathrm{MP} 2 / 6-311 \mathrm{G}^{* *}\right)$ is larger in magnitude than $\Delta E_{\text {tot }}(\mathrm{SIBFA})$ by a similar amount as prior to inclusion of correlation/dispersion, namely, in the range $41-51$ $\mathrm{kcal} / \mathrm{mol}$ out of 1000 . This difference should, correspondingly, be significantly reduced after the BSSE correction, for which a lower bound is given by the corresponding HF BSSE values, namely, a $30-40 \mathrm{kcal} / \mathrm{mol}$ range. As a consequence, $\Delta E_{\mathrm{tot}}(\mathrm{SIB}-$
FA) would differ from $\Delta E\left(\mathrm{MP} 2 / 6-311 \mathrm{G}^{* *}\right)$ by less than $20 \mathrm{kcal} /$ mol out of 1000 . The trends of $\Delta E\left(\mathrm{MP} 2 / 6-311 \mathrm{G}^{* *}\right)$ listed in Table 4 for the five complexes appear closely matched by $\Delta E_{\mathrm{tot}}(\mathrm{SIBFA})$. On the other hand, surprisingly, the values of $\Delta E(\mathrm{DFT} / \mathrm{PBE})$ have smaller magnitudes than those of $\Delta E(\mathrm{HF})$.

(b) Energy Values in the Presence of the Zn Binding Site. $\triangle E$ (SIBFA) differs from $\Delta E(\mathrm{HF} / \mathrm{CEP} 4-31 \mathrm{G}(2 \mathrm{~d}))$ by differences in the range $36-42 \mathrm{kcal} / \mathrm{mol}$ out of 1500 . Again, this difference should be reduced after BSSE corrections. A lower bound for the BSSE correction is given by its summed values in the EDMA, Mg(II), and Zn(II) sites, namely, $22 \mathrm{kcal} / \mathrm{mol}$. Such a difference would then be reduced to $14-20 \mathrm{kcal} / \mathrm{mol}$ out of 
1500 . The increase by $\sim 35 \mathrm{kcal} / \mathrm{mol}$ of $E_{\mathrm{ct}}(\mathrm{SIBFA})$ corresponds mainly to the value of this contribution in the actual $\mathrm{Zn}$ binding site (Table 2). Similarly, the corresponding $E_{\mathrm{pol}}(\mathrm{SIBFA})$ gains of $\sim 68 \mathrm{kcal} / \mathrm{mol}$ reflect to a large part the value of this contribution in this site. The trends of $\Delta E(\mathrm{QC})$ upon single fragment or water removal are correctly reproduced by $\Delta E(\mathrm{SIBFA})$, as shown in Figure $6 \mathrm{~b}$.

\section{Conclusions}

We have resorted to the SIBFA polarizable molecular mechanics (PMM) to analyze the binding energies of a diphosphate inhibitor, $N, N$-dimethyl-2-amino-1-ethyl diphosphate (NIPP), to the recognition site of a $\mathrm{Zn} / \mathrm{Mg}$ bimetallic enzyme, isopentenyl diphosphate isomerase (IDI). Diphosphate entities are also encountered in the structures of farnesyl transferase substrates, ${ }^{49,50}$ and a series of cationic bisphosphonate derivatives were recently developed as dual inhibitors of farnesyl/geranylgeranyl diphosphate synthase. ${ }^{11}$ These findings are an incentive to apply PMM approaches in order to model the complexes of such inhibitors to these metallo-enzymes. It is recalled ${ }^{9}$ that a single-point SIBFA computation on complexes of about 150 atoms takes less than a second of IBM Power5 monoprocessor time. It requires several hours with high-level QC, particularly with extended basis sets.

The recognition site of IDI totals 13 amino acid residues and 115 atoms and has in addition two divalent metal cations and two structural water molecules. The NIPP inhibitor encompasses 25 atoms. Comparisons with parallel QC computations have evaluated the ability of PMM to reproduce the QC interaction energies at uncorrelated and at correlated levels, and their trends upon "mutating" the site by removing from it selected residues as well as the two $\mathrm{Mg}$ (II)-bound water molecules. Related analyses were previously reported regarding the complexes of a nonhydrolyzable analogue of ATP and the recognition site of the HPPK kinase, ${ }^{7}$ and the complexes of inhibitors with Zn-metalloproteins. ${ }^{8,9}$ In the present work, we have extended such comparisons to each of the three major IDI recognition sites: the ethyldimethylammonium (EDMA) and the $\mathrm{Zn}$ (II) and $\mathrm{Mg}$ (II) binding sites. The first is stabilized by both ionic and cation $-\pi$ interactions. The second is a recurrent "soft" cation binding site but has the unusual presence of two hard carboxylate ligands. The third is a strongly ionic site, in which a "hard" dication is bound by the trianionic diphosphate moiety of the ligand and by one carboxylate group. Comparisons with RVS energy decompositions at the HF level and with MP2 and DFT computations at the correlated level were performed. This has also enabled the three different basis sets CEP 4-31G(2d), 6-311G**, and cc-pVTZ to be compared. A very important result relates to the close numerical agreements between all three basis sets when BSSE effects are accounted for, both at uncorrelated and at correlated levels. The only divergences between the three basis sets are related to the values of $E_{\text {corr }}$ in the polycoordinated complexes of the "soft" $\mathrm{Zn}$ (II) cation.

In the three model binding sites as well as in the NIPP binding site, SIBFA was found to give good agreements with the QC results. These were not limited to the CEP 4-31G(2d) basis set, on which it was originally calibrated, but applied to the two largest basis sets as well, provided BSSE corrections were performed. Nevertheless, there were three caveats.

(a) Underestimation of $E_{\mathrm{ct}}(\mathrm{RVS})$ by $E_{\mathrm{ct}}(\mathrm{SIBFA})$ in the EDMA binding site. This feature has precedents in other complexes of a charged ammonium entity. ${ }^{25 b, 38}$ In this, as well as in these previous studies, the impact on $\Delta E$ was limited, however, owing to compensation by the $E_{\mathrm{pol}}$ and/or $E_{1}$. A severe underestimation of $\Delta E(\mathrm{QC})$ is nevertheless expected at distances of approach shorter than equilibrium. Therefore, a search for an improved representation of the weight of the heavy atom in the antibonding orbital of the electron acceptor will be necessary for $E_{\mathrm{ct}}(\mathrm{SIBFA})$ to be able to cover such distances.

(b) Need for an improved representation of the lone pairs of di- and trianionic phosphate, and how these are affected by conjugation when integrated in a larger molecular entity. Approaches such as $\mathrm{ELF}^{47}$ are instrumental toward such an improvement. ELF analyses on biologically relevant complexes were recently done in our laboratories ${ }^{51}$ and will be extended to such groups. It is noted that issues a and b do not arise in other PMM procedures than SIBFA, since to our knowledge there are no other ones which seek to represent the overlapdependent contributions $E_{\text {rep }}$ and $E_{\mathrm{ct}}$ with explicit lone-pair centroids.

(c) In polyligated complexes of "soft" divalent cations, absence of nonadditivity in the present formulation of $E_{\text {disp. }}$ This could possibly be remedied by resorting to correlated multipoles and polarizabilities, as undertaken in ref $25 \mathrm{~b}$. Resorting to the Axilrod-Teller formula ${ }^{52}$ could also constitute another attractive possibility in such complexes. It does not seem to have been considered in any of the contemporary force fields, whether polarizable or nonpolarizable. Correlated QC computations such as the ones reported could constitute a benchmark for its implementation.

Finally, the present calculations could be used to benchmark other PMM or semiempirical approaches. For that purpose, the coordinates of the investigated complexes are available upon request.

Acknowledgment. The computations reported in this work were performed using resources from GENCI (CINES/IDRIS), grant 2009-075009, and the Centre de Ressources Informatiques de Haute Normandie (CRIHAN, Rouen, France), grant 1998053. We wish to thank the Reviewers for constructive criticism. One of us (N.G.) wishes to dedicate this paper to the memory of the late Dr. Morris Krauss, who passed away in May 2009.

Supporting Information Available: Superimposition of the SIBFA energy-minimized structure of the IDI-NIPP complex with the X-ray structure. This material is available free of charge via the Internet at http://pubs.acs.org.

\section{References and Notes}

(1) (a) Rohmer, M. Nat. Prod. Rep. 1999, 16, 565. (b) Rohdich, F.; Bacher, A.; Eisenreich, W. Bioorg. Chem. 2004, 32, 392.

(2) (a) Wouters, J.; Oudjama, Y.; Barkley, S.; Tricot, C.; Stalon, V.; Droogmans, L.; Poulter, C. D. J. Biol. Chem. 2003, 278, 11903. (b) De Ruyck, J.; Pouyez, J.; Rothman, S. C.; Poulter, C. D.; Wouters, J. Biochemistry 2008, 47, 9051.

(3) (a) Concha, N. O.; Rasmussen, B. A.; Bush, K.; Herzberg, O. Structure 1996, 4, 823. (b) Carfi, A.; Pares, S.; Duee, E.; Galleni, M.; Duez, C.; Frère, J.-M.; Dideberg, O. EMBO J. 1995, 14, 4914.

(4) Ma, J. C.; Dougherty, D. A. Chem. Rev. 1997, 97, 1303.

(5) Silman, I.; Sussman, J. L. Curr. Opin. Pharmacol. 2005, 5, 1.

(6) Bennett, L.; Glaudemans, C. Biochemistry 1979, 18, 3337.

(7) Gresh, N.; Shi, G.-B. J. Comput. Chem. 2004, 25, 160. 1131 .

(8) Antony, J.; Piquemal, J.-P.; Gresh, N. J. Comput. Chem. 2005, 26,

(9) Roux, C.; Gresh, N.; Perera, L. E.; Piquemal, J. P.; Salmon, L. J. Comput. Chem. 2007, 28, 938.

(10) Monkkonen, H.; Auriola, S.; Lehendari, P.; Kellinsalmi, M.; Hassinen, I. E.; Vepsalainen, J.; Monkonnen, J. Br. J. Pharmacol. 2006, 147, 437.

(11) Zhang, Y.; et al. J. Am. Chem. Soc. 2009, 131, 5153.

(12) Stevens, W. J.; Fink, W. Chem. Phys. Lett. 1987, 139, 15.

(13) Stevens, W. J.; Basch, H.; Krauss, M. J. Chem. Phys. 1984, 81, 6026.

(14) Garmer, D. R.; Gresh, N. J. Am. Chem. Soc. 1994, 116, 3556. 
(15) Dunning, T. H., Jr. J. Chem. Phys. 1989, 90, 1007.

(16) (a) Becke, A. D. J. Chem. Phys. 1988, 88, 1053. (b) Lee, C.; Yang, W.; Parr, R. G. Phys. Rev. 1988, B37, 785. (c) Becke, A. J. Chem. Phys. 1993, 98, 5648.

(17) (a) Perdew, J. W.; Burke, K.; Ernzerhof, M. Phys. Rev. Lett. 1996, 77, 3865. (b) Perdew, J. W.; Burke, K.; Ernzerhof, M. Phys. Rev. Lett. 1997, 78, 1396.

(18) Pople, J. A.; Binkley, J. S.; Seeger, R. Int. J. Quantum Chem. 1976, Symp. 10, 1.

(19) (a) Boys, S. F.; Bernardi, F. Mol. Phys. 1970, 19, 553. (b) Cammi, R.; Hoffmann, H. J.; Tomasi, J. Theor. Chim. Acta 1989, 76, 297.

(20) Frisch, M. J.; Trucks, G. W.; Schlegel, H. B.; Scuseria, G. E.; Robb, M. A.; Cheeseman, J. R.; Montgomery, J. A., Jr.; Vreven, T.; Kudin, K. N.; Burant, J. C.; Millam, J. M.; Iyengar, S. S.; Tomasi, J.; Barone, V.; Mennucci, B.; Cossi, M.; Scalmani, G.; Rega, N.; Petersson, G. A.; Nakatsuji, H.; Hada, M.; Ehara, M.; Toyota, K.; Fukuda, R.; Hasegawa, J.; Ishida, M.; Nakajima, T.; Honda, Y.; Kitao, O.; Nakai, H.; Klene, M.; Li, X.; Knox, J. E.; Hratchian, H. P.; Cross, J. B.; Bakken, V.; Adamo, C.; Jaramillo, J.; Gomperts, R.; Stratmann, R. E.; Yazyev, O.; Austin, A. J.; Cammi, R.; Pomelli, C.; Ochterski, J. W.; Ayala, P. Y.; Morokuma, K.; Voth, G. A.; Salvador, P.; Dannenberg, J. J.; Zakrzewski, V. G.; Dapprich, S.; Daniels, A. D.; Strain, M. C.; Farkas, O.; Malick, D. K.; Rabuck, A. D.; Raghavachari, K.; Foresman, J. B.; Ortiz, J. V.; Cui, Q.; Baboul, A. G.; Clifford, S.; Cioslowski, J.; Stefanov, B. B.; Liu, G.; Liashenko, A.; Piskorz, P.; Komaromi, I.; Martin, R. L.; Fox, D. J.; Keith, T.; Al-Laham, M. A.; Peng, C. Y.; Nanayakkara, A.; Challacombe, M.; Gill, P. M. W.; Johnson, B.; Chen, W.; Wong, M. W.; Gonzalez, C.; Pople, J. A. Gaussian 03, revision C.02; Gaussian, Inc.: Wallingford, CT, 2007.

(21) Grimme, S. J. Chem. Phys. 2006, 124, 034108.

(22) Frisch, M. J.; Trucks, G. W.; Schlegel, H. B.; Scuseria, G. E.; Robb, M. A.; Cheeseman, J. R.; Scalmani, G.; Barone, V.; Mennucci, B.; Petersson, G. A.; Nakatsuji, H.; Caricato, M.; Li, X.; Hratchian, H. P.; Izmaylov, A. F.; Bloino, J.; Zheng, G.; Sonnenberg, J. L.; Hada, M.; Ehara, M.; Toyota, K.; Fukuda, R.; Hasegawa, J.; Ishida, M.; Nakajima, T.; Honda, Y.; Kitao, O.; Nakai, H.; Vreven, T.; Montgomery, J. A., Jr.; Peralta, J. E.; Ogliaro, F.; Bearpark, M.; Heyd, J. J.; Brothers, E.; Kudin, K. N.; Staroverov, V. N.; Kobayashi, R.; Normand, J.; Raghavachari, K.; Rendell, A.; Burant, J. C.; Iyengar, S. S.; Tomasi, J.; Cossi, M.; Rega, N.; Millam, J. M.; Klene, M.; Knox, J. E.; Cross, J. B.; Bakken, V.; Adamo, C.; Jaramillo, J.; Gomperts, R.; Stratmann, R. E.; Yazyev, O.; Austin, A. J.; Cammi, R.; Pomelli, C.; Ochterski, J. W.; Martin, R. L.; Morokuma, K.; Zakrzewski, V. G.; Voth, G. A.; Salvador, P.; Dannenberg, J. J.; Dapprich, S.; Daniels, A. D.; Farkas, O.; Foresman, J. B.; Ortiz, J. V.; Cioslowski, J.; Fox, D. J. Gaussian 09, revision A.1; Gaussian, Inc.: Wallingford, CT, 2009.

(23) Schmidt, M. W.; Baldridge, K. K.; Boatz, J. A.; Elbert, S. T. Gordon, M. S.; Jensen, J. H.; Koseki, S.; Matsunaga, N.; Nguyen, K. A.; Su, S.; Windus, T. L.; Dupuis, M.; Montgomery, J. A., Jr. J. Comput. Chem. 1993, 14, 1347.

(24) (a) Gresh, N.; Claverie, P.; Pullman, A. Theor. Chim. Acta 1984, 66, 1. (b) Gresh, N. J. Comput. Chem. 1995, 16, 856. (c) Gresh, N.; Cisneros, G. A.; Darden, T. A.; Piquemal, J. P. J. Chem. Theory Comput. 2007, 3, 1960 .

(25) (a) Piquemal, J. P.; Gresh, N.; Giessner-Prettre, C. J. Phys. Chem. A 2003, 107, 10353. (b) Piquemal, J.-P.; Chevreau, H.; Gresh, N. J. Chem. Theory Comput. 2007, 3, 824.

(26) Vigné-Maeder, F.; Claverie, P. J. Chem. Phys. 1988, 88, 4934.

(27) Garmer, D. R.; Stevens, W. J. J. Phys. Chem. A 1989, 93, 8263.

(28) Evangelakis, G. A.; Rizos, J. P.; Lagaris, I. E.; Demetropoulos, I. N. Comput. Phys. Commun. 1987, 46, 401.
(29) Jenkins, L. M. M.; Hara, T.; Durrell, S. R.; Hayashi, R.; Imman, J. K.; Piquemal, J.-P.; Gresh, N.; Appella, E. J. Am. Chem. Soc. 2007, 129, 1106.

(30) Langlet, J.; Claverie, P.; Caillet, J.; Pullman, A. J. Phys. Chem. 1988, 92, 1617.

(31) Gresh, N.; Piquemal, J.-P.; Krauss, M. J. Comput. Chem. 2005, $26,1113$.

(32) Claverie, P.; Daudey, J. P.; Langlet, J.; Pullman, B.; Piazzola, D.; Huron, M. J. J. Phys. Chem. 1978, 82, 405.

(33) Gresh, N.; Pullman, B. Biochim. Biophys. Acta 1980, 625, 356.

(34) (a) Bash, H.; Stevens, W. J. THEOCHEM 1995, 338, 303. (b) Pullman, A.; Berthier, G.; Savinelli, R. J. Am. Chem. Soc. 1998, $120,8553$. (c) Pullman, A.; Berthier, G.; Savinelli, R. J. Comput. Chem. 1997, 18 , 2012.

(35) (a) Caldwell, J. W.; Kollman, P. A. J. Am. Chem. Soc. 1995, 117, 4177. (b) Cubero, E.; Lucque, F. J.; Orozco, M. Proc. Natl. Acad. Sci. U.S.A. 1998, 95, 9576. (c) Dehez, F.; Angyan, J. G.; Gutierrez, I. S.; Luque, F. J.; Schulten, K.; Chipot, C. J. Chem. Theory Comput. 2007, 3, 1914.

(36) (a) Sponer, J.; Sabat, M.; Burda, J.; Leszczynski, J.; Hobza, P. J. Phys. Chem. B 1999, 103, 2528. (b) Hobza, P.; Sponer, J. Chem. Rev. 1999, 99, 3247. (c) Hobza, P.; Sponer, J. J. Am. Chem. Soc. 2002, 124, 11802. (37) (a) Grimme, S. J. Comput. Chem. 2006, 27, 1787. (b) Jurecka, P.; Cerny, J.; Hobza, P.; Salahub, D. R. J. Comput. Chem. 2007, 28, 555. (c) Marom, N.; Tkatchenko, A.; Scheffler, M.; Kronik, L. J. Chem. Theory Comput. 2010, 6, 81 .

(38) Gresh, N.; Leboeuf, M.; Salahub, D. R. Modelling the Hydrogen Bond; ACS Symposium Series 569; Smith, D. A., Ed.; American Chemical Society: Washington, DC, 1994; p 82.

(39) (a) Gresh, N.; Claverie, P.; Pullman, A. Int. J. Ouantum Chem. 1982, 22, 199. (b) Gresh, N.; Claverie, P.; Pullman, A. Int. J. Quantum Chem. 1986, 29, 101.

(40) (a) Tiraboschi, G.; Gresh, N.; Giessner-Prettre, C.; Pedersen, L. G.; Deerfield, D. W. J. Comput. Chem. 2000, 21, 1011. (b) Tiraboschi, G.; Roques, B. P.; Gresh, N. J. Comput. Chem. 1999, $20,1379$.

(41) de Courcy, B.; Piquemal, J. P.; Gresh, N. J. Chem. Theory Comput. 2008, 4, 1659.

(42) Rogalewicz, F.; Gresh, N.; Ohanessian, G. J. Comput. Chem. 2000, 21, 963.

(43) Tiraboschi, G.; Fournie-Zaluski, M. C.; Roques, B. P.; Gresh, N. J. Comput. Chem. 2001, 22, 1038.

(44) (a) Gresh, N.; Policar, C.; Giessner-Prettre, C. J. Phys. Chem. A 2002, 106, 5660. (b) Ledecq, M.; Lebon, F.; Durant, F.; Giessner-Prettre, C.; Marquez, A.; Gresh, N. J. Phys. Chem. B 2003, 107, 10640.

(45) Faerman, C. H.; Price, S. L. J. Am. Chem. Soc. 1990, 112, 4915.

(46) Foret, J.; deCourcy, B.; Gresh, N.; Piquemal, J.-P.; Salmon, L. Bioorg. Med. Chem. 2009, 17, 7100.

(47) (a) Becke, A. D.; Edgecombe, K. E. J. Chem. Phys. 1990, 92, 5397. (b) Silvi, B.; Savin, A. Nature (London) 1994, 371, 683.

(48) Gresh, N.; Garmer, D. R. J. Comput. Chem. 1996, 17, 1481.

(49) (a) Sousa, S. F.; Fernandes, P. A.; Ramos, M. J. Proteins 2007, 66, 205. (b) Sousa, S. F.; Fernandes, P. A.; Ramos, M. J. Chem.-Eur. J. 2009, 15, 4243. (c) Sousa, S. F.; Fernandes, P. A.; Ramos, M. J. Bioorg. Med. Chem. 2009, 17, 3369.

(50) Ho, M.-H.; De Vivo, M.; Dal Peraro, M.; Klein, M. L. J. Chem. Theory Comput. 2009, 5, 1567.

(51) de Courcy, B.; Gresh, N.; Piquemal, J.-P. Interdiscip. Sci.: Comput. Life Sci. 2009, 1, 55.

(52) Axilrod, B. M.; Teller, E. J. Chem. Phys. 1943, 11, 299.

JP907629K 